\title{
Wnt/B-Catenin Signaling as a Driver of Hepatocellular Carcinoma Progression: An Emphasis on Molecular Pathways
}

\author{
Mahshid Deldar Abad Paskeh ${ }^{1,2}$ \\ Sepideh Mirzaei ${ }^{3}$ \\ Milad Ashrafizadeh ${ }^{4,5}$ \\ Ali Zarrabi ${ }^{5,6}$ \\ Gautam Sethi ${ }^{7,8}$ \\ 'Department of Genetics, Faculty of \\ Advanced Science and Technology, \\ Tehran Medical Sciences, Islamic Azad \\ University, Tehran, Iran; ${ }^{2}$ Farhikhtegan \\ Medical Convergence Sciences Research \\ Center, Farhikhtegan Hospital, Tehran \\ Medical Sciences, Islamic Azad University, \\ Tehran, Iran; ${ }^{3}$ Department of Biology, \\ Faculty of Science, Islamic Azad \\ University, Science and Research Branch, \\ Tehran, Iran; ${ }^{4}$ Faculty of Engineering and \\ Natural Sciences, Sabanci University, \\ Tuzla, Istanbul, Turkey; ${ }^{5}$ Sabanci \\ University Nanotechnology Research and \\ Application Center (SUNUM), Tuzla, \\ Istanbul, Turkey; ${ }^{6}$ Department of \\ Biomedical Engineering, Faculty of \\ Engineering and Natural Sciences, Istinye \\ University, Sariyer, Istanbul, 34396, \\ Turkey; ${ }^{7}$ Department of Pharmacology, \\ Yong Loo Lin School of Medicine, \\ National University of Singapore, \\ Singapore; ${ }^{8} \mathrm{C}$ ancer Translational \\ Research Programme, Yong Loo Lin \\ School of Medicine, National University \\ of Singapore, Singapore
}

Correspondence: Sepideh Mirzaei Department of Biology, Faculty of Science, Islamic Azad University, Science and Research Branch, Tehran, Iran Email Sepideh.mirzaei@srbiau.ac.ir

Gautam Sethi

Department of Pharmacology, Yong Loo Lin School of Medicine, National University of Singapore, Singapore Email phcgs@nus.edu.sg

\begin{abstract}
Liver cancers cause a high rate of death worldwide and hepatocellular carcinoma (HCC) is considered as the most common primary liver cancer. HCC remains a challenging disease to treat. Wnt $/ \beta$-catenin signaling pathway is considered a tumor-promoting factor in various cancers; hence, the present review focused on the role of Wnt signaling in HCC, and its association with progression and therapy response based on pre-clinical and clinical evidence. The nuclear translocation of $\beta$-catenin enhances expression level of genes such as c-Myc and MMPs in increasing cancer progression. The mutation of CTNNB1 gene encoding $\beta$-catenin and its overexpression can lead to HCC progression. $\beta$-catenin signaling enhances cancer stem cell features of HCC and promotes their growth rate. Furthermore, $\beta$ catenin prevents apoptosis in HCC cells and increases their migration via triggering EMT and upregulating MMP levels. It is suggested that $\beta$-catenin signaling participates in mediating drug resistance and immuno-resistance in HCC. Upstream mediators including ncRNAs can regulate $\beta$-catenin signaling in HCC. Anti-cancer agents inhibit $\beta$-catenin signaling and mediate its proteasomal degradation in HCC therapy. Furthermore, clinical studies have revealed the role of $\beta$-catenin and its gene mutation $(C T N B B 1)$ in HCC progression. Based on these subjects, future experiments can focus on developing novel therapeutics targeting Wnt/ $\beta$-catenin signaling in HCC therapy.
\end{abstract}

Keywords: liver cancer, drug resistance, immunotherapy, Wnt signaling, non-coding RNAs

\section{Introduction}

Liver cancers are the fourth most common cancer worldwide. ${ }^{1,2}$ Primary liver cancers are responsible for a major challenge in developed and developing countries and are correlated with clinical, economic, and psychological burden. ${ }^{3}$ Hepatocellular carcinoma (HCC) is a troublesome problem for healthcare providers and comprises up to $85-90 \%$ of primary liver cancers. The risk factors for HCC are different based on region and country. For instance, chronic infection with hepatitis B virus (HBV), alcohol intake, and hepatitis C virus (HCV) lead to development of HCC. Risk factors are different in different countries, different genetic landscape and molecular subtype; and clinical emergence of HCC also varies based on region. ${ }^{4-7}$ Antiviral treatment and HBV vaccination are considered as promising strategies to prevent HCC development. ${ }^{8,9}$ Furthermore, advances in diagnosis and treatment of HCC have resulted in a significant decrease $(20.3 \%)$ in mortality caused by HCC from 1990 to $2017 .{ }^{10}$ There are some therapeutic strategies for HCC including liver resection, ablation and transplantation that show efficacy in 
early stages of this malignant tumor. Unfortunately, in spite of advances in diagnostic methods, HCC patients are often diagnosed in advanced stages, when therapy is almost impossible. ${ }^{11,12}$ Therefore, novel imaging methods should be applied in HCC diagnosis. For instance, patients who have cirrhosis, are advised to be screened in terms of HCC development. ${ }^{13}$ Besides, plasma, serum, and urine can be considered valuable sources for HCC diagnosis. ${ }^{14}$ Due to diagnosis of $\mathrm{HCC}$ at advanced stages, risk of recurrence and metastatic nature of cancer cells, HCC patients have a 5 -year survival rate of less than $50 \%{ }^{15}$ The incidence rate of $\mathrm{HCC}$ is more prevalent in developing countries compared to developed ones, so up to $85 \%$ of HCC cases are observed in Eastern Asia and Africa. ${ }^{11,16-18}$ In addition to lifestyle (alcohol consumption) and environmental factors (infection) that were mentioned previously, genetic and epigenetic alterations play a key role in development of HCC. ${ }^{19}$

Recent experiments have been directed toward elucidating signaling networks involved in HCC progression and understanding their interaction as potential therapeutic targets. ${ }^{19,20}$ The metastatic nature of HCC cells results in undesirable prognosis of patients. The epithelial-tomesenchymal transition (EMT) is responsible for metastasis and migration of HCC cells. ${ }^{21,22}$ Sphingosine-1-phosphate receptor-1 (S1PR1) undergoes upregulation in HCC to induce EMT-mediated migration. ${ }^{23}$ The long noncoding RNA (lncRNA) SPRY4-IT1 regulates tumor necrosis factor (TNF) signaling in mediating EMT in HCC. ${ }^{24}$ The matrix metalloproteinases (MMPs) also participate in invasiveness of $\mathrm{HCC}$ cells, so that ADAM17 induces MMP-21 expression that is in favor of increasing $\mathrm{HCC}$ progression. $^{25}$ As mentioned, lncRNAs regulate HCC progression. Notably, microRNAs (miRNAs) also affect malignancy of HCC cells. For instance, miRNA-16 and miRNA-375 undergo upregulation by thymoquinone as anti-tumor agent to suppress HCC progression. ${ }^{26}$ Besides, circular RNA (circRNA)-102272 reduces expression level of miRNA-326 to enhance HCC growth and mediate their resistance to cisplatin chemotherapy. ${ }^{27}$ The activation of PI3K/Akt axis enhances glycolysis of $\mathrm{HCC}$ cells to induce sorafenib resistance. ${ }^{28}$ Each experiment provides a unique pathway that is responsible for $\mathrm{HCC}$ progression. For instance, SIX4 elevates migration and invasion of HCC cells via upregulating YAP1 and c-MET overexpression. Furthermore, hepatocyte growth factor as ligand of c-MET is capable of promoting SIX4 expression in aggravating HCC metastasis. ${ }^{29}$ The stabilization of STOML2 enhances PINK1 stability to induce metastasis of $\mathrm{HCC}$ cells and reduce their sensitivity to lenvatinib chemotherapy. ${ }^{30}$ ENO1 can be transferred using exosomes to $\mathrm{HCC}$ cells and by enhancing integrin $\alpha 6 \beta 4$ expression, ENO1 is involved in increasing migration and invasion. ${ }^{31}$ The upregulation of SF3B1 favors HCC progression and significantly enhances survival of these malignant cells. ${ }^{32}$ The interactions among signaling networks can affect HCC progression. For instance, circ-0001175 reduces miRNA-130a-5p expression to upregulate SNX5 that is of importance for promoting proliferation rate of HCC cells. ${ }^{33}$ Down-regulation of RSK2 due to mutations result in MAPK signaling activation, promoting cholesterol metabolism and subsequent increase in proliferation of HCC cells. ${ }^{34}$

Therefore, a variety of genetic and epigenetic alterations can mediate the progression of HCC cells. ${ }^{35-38}$ In respect to this, we allotted the present review to reveal the role of $\beta$-catenin signaling in HCC. First, we provided an overview of $\beta$-catenin signaling and its major role in oncology. Then, we examined activation of $\beta$-catenin in $\mathrm{HCC}$ and its association with proliferation, metastasis, and therapy response. Then, we shed some light on the regulation of $\beta$-catenin signaling in HCC by upstream mediators in which miRNAs, lncRNAs and circRNAs are the most well-known ones. Next, we demonstrated how $\beta$-catenin signaling can be affected via pharmacological and genetic approaches. Finally, we provided insights for clinical application of $\beta$-catenin as diagnostic and prognostic tool.

\section{Beta-Catenin: Signaling and Cancer Function}

$\beta$-catenin is encoded by CTNNB1 gene in humans and is considered a multifunctional protein, as vertebrate homo$\log$ of Drosophila Armadillo. ${ }^{39} \beta$-catenin is a key member of catenin family proteins and is involved in intracellular adhesion. $\beta$-catenin is a part of Wnt signaling and participates in physiological processes including embryonic development and tissue homeostasis. Notably, $\beta$-catenin can function as a transcription activator upon coupling with $\mathrm{T}$ cell factor/lymphoid enhancer factor (TCF/LEF) proteins with capacity to bind to DNA. ${ }^{40}$ Structurally, $\beta$ catenin in humans consists of 781 amino acids that have a central structural core containing 12 armadillo repeats and intrinsically disordered $\mathrm{N}$ - and C-terminal regions. ${ }^{41}$ There is a positively charged groove in 12 superhelical armadillo repeats that provides a binding site for $\beta$-catenin 
cooperators including TCF, Axin and APC. ${ }^{42}$ The $\mathrm{N}$-terminal domain can undergo phosphorylation by casein kinase-1 (CK-1) and glycogen synthase kinase-3 $\beta$ (GSK$3 \beta$ ), determining $\beta$-catenin stability. The C-terminal domain is responsible for interacting with transcriptional co-activators and co-repressors. ${ }^{43,44}$ The biological investigations revealed that armadillo repeat domains are essential for interaction of $\beta$-catenin with its ligands. In fact, armadillo repeats provide protein-protein interaction capacity of $\beta$-catenin and its ability to form complexes. It has been reported that $\beta$-catenin can produce complexes with APC, Axin, ICAT, LEF1, TCF3, TCF4 and BCL9. ${ }^{45}$

Normally, $\beta$-catenin is present in cytoplasmic side of adherence junctions in epithelial cells with close contact with cadherins complex. ${ }^{46}$ However, cytoplasmic $\beta$ catenin undergoes ubiquitination to be degraded by proteasomal route. ${ }^{47,48}$ Therefore, the first impact of Wnt ligands is to enhance stability of $\beta$-catenin protein and prevent its degradation. ${ }^{49}$ The Wnt ligands can bind to FZD-LRP5/6 receptors on surface of cells to prevent phosphorylation of $\beta$-catenin and mediate its dissociation from destruction complex. ${ }^{50}$ The destruction complex consists of GSK-3 $\beta$, Adenomatous polyposis coli (APC), Axin and CK1 that mediate proteasomal degradation of $\beta$-catenin protein. ${ }^{51}$ Therefore, Wnt ligands inhibit $\beta$-catenin degradation, enhance its accumulation in cytoplasm, and mediate its nuclear translocation, where $\beta$-catenin can bind to transcription factors including TCF-LEF family. ${ }^{47,52-54}$ This is called canonical or $\beta$-catenin dependent pathway of Wnt signaling (Figure 1).

The tumor-promoting role of $\beta$-catenin in different cancers has been revealed. $\beta$-catenin is able to reduce expression of miRNA-455-3p in mediating m6A modification of HSF1. Then, nuclear translocation of $\beta$-catenin occurs to enhance colorectal cancer progression. ${ }^{55}$ UBE2T is able to induce ubiquitination of RACK1 at the lysine K172 to enhance its degradation, leading to activation of $\mathrm{Wnt} / \beta$-catenin and subsequent increase in gastric cancer progression. ${ }^{56} \beta$-catenin signaling also participates in drug resistance feature of cancer cells. ${ }^{57} \beta$-catenin is able to stimulate autophagy and mediate temozolomide resistance of glioblastoma. ${ }^{58}$ Furthermore, 5-fluorouracil (5-FU) increases stemness of colorectal tumor cells by triggering Wnt/ $\beta$-catenin axis. ${ }^{59}$ IncRNA SNHG11 interacts with Cullin $4 \mathrm{~A}$ to mediate ubiquitination and degradation of GSK-3 $\beta$, resulting in Wnt/ $\beta$-catenin activation. ${ }^{60}$ The interesting point is the interaction of $\beta$-catenin with the immune system. The expression level of programmed death-ligand 1 (PD-L1) undergoes upregulation by $\beta$ catenin to reduce cytotoxicity and infiltration of $\mathrm{CD} 8+$ $\mathrm{T}$ cells, resulting in immune evasion of glioblastoma cells. $^{61}$ The inhibition of $\mathrm{Wnt} / \beta$-catenin signaling by ISG12a leads to PD-L1 inactivation and subsequent cytotoxicity of natural killer (NK) cells. ${ }^{62}$ Furthermore, $\beta$ catenin inhibition along with immunotherapy synergistically suppress colorectal tumor progression. ${ }^{63}$ The Wnt/ $\beta$ catenin axis can also promote migration and invasion of cancer cells via mediating EMT mechanism. ${ }^{64}$ The knockdown of lncRNA AFAP1-AS1 by nanostructures can suppress $\beta$-catenin signaling to promote potential of radiotherapy in breast cancer suppression. ${ }^{65}$ Hence, $\beta$-catenin has an oncogenic role and its inhibition should be performed to delay tumor growth.

\section{Beta-Catenin and Hepatocellular Carcinoma Beta-Catenin Expression Status and
Mutation: Clinical Association}

As $\beta$-catenin has an oncogenic role, its expression level should undergo upregulation in HCC. Furthermore, $\beta$ catenin mutation is an obvious finding that has been confirmed in various experiments. ${ }^{66,67}$ An experiment has evaluated association between $\beta$-catenin mutation and HCC progression. This study demonstrated positive association between $\beta$-catenin mutation and high-grade differentiation in HCC. Furthermore, $\beta$-catenin mutation significantly enhances pseudoglandular proliferation and bile production in HCC. ${ }^{68}$ Due to abnormal localization and $\beta$-catenin mutation, the generation of truncated $\beta$ catenin proteins increases, which favors HCC development. ${ }^{69}$ Both conventional and missense mutations are able to affect $\beta$-catenin expression in HCC and mediate its progression. It has been reported that conventional mutations in codons 33, 37, 41 and 45 are observed in $12.8 \%$ of HCC patients. Other missense mutations can occur in codons 32, 34 and 35. Therefore, conventional and other missense mutations in CTNBB1 gene can enhance $\beta$-catenin expression and trigger its nuclear translocation. ${ }^{70}$ Another experiment has revealed somatic mutation of $\beta$-catenin in $12 \%$ of HCC cases. These mutations occurred in exon 3 that affects phosphorylation and ubiquitination of $\beta$-catenin, leading to a significant increase in its stability and expression. Furthermore, gene mutation results in increased nuclear translocation of $\beta$ catenin protein occurring in $17 \%$ of HCC cases. Finally, 
a nonnuclear type overexpression of $\beta$-catenin (cytoplasm or cytoplasmic membrane overexpression) can occur, showing that $\beta$-catenin upregulation in HCC is heterogenous. $^{71}$

As exon $3 \beta$-catenin mutation is common in HCC and enhances its progression, glutamine synthase staining can be utilized for its detection. ${ }^{72}$ Another experiment has evaluated $\beta$-catenin mutation in Chinese people. The mRNA expression of $\beta$-catenin gene exon 3 undergoes overexpression in HCC compared to para-cancerous and normal liver tissues. The mutation of $\beta$-catenin occurs in $44.1 \%$ of HCC cases in Chinese people and its enhanced accumulation in cytoplasm or nucleus is observed in $61.8 \%$ of $\mathrm{HCC}$ cases. $^{73}$ However, an experiment $^{2}$ provided contradictory results, showing that $\beta$-catenin mutation impairs HCC progression. This study revealed that cytokeratin 19 (CK19) overexpression leads to HCC progression and $\beta$-catenin mutation reduces its carcinogenesis impact. ${ }^{74}$ Although this study provided controversial findings, it needs more investigation to show whether $\beta$ catenin mutation favors HCC progression or not. Furthermore, the incidence rate of $\beta$-catenin mutation varies based on region, race, and country. For instance, $\beta$ catenin mutation occurs in China, Japan and Europe, but its mutation does not occur in Southern African blacks with HCC. ${ }^{75}$ The mutation of CTNNB1 gene occurs in
$18.1 \%$ of cases of $\mathrm{HCC}$, based on a new experiment, and its mutation frequency is higher in non-viral HCC (29.4\%) compared to HBV-related cases $(12.4 \%)$. There is a missense point mutation found in exon 3 of CTNNB1 gene with higher frequency in codons $32,33,38$ and $45 .^{76}$ Notably, CTNNB1 gene mutation shows positive response with immune inhibitors in HCC. It also affects infiltration of neutrophils and natural killer cells in tumor microenvironment. Therefore, it can be considered as a reliable biomarker for HCC response to immunotherapy. ${ }^{77}$ Next generation sequencing (NGS) seems to be beneficial in clinical course and for treatment of HCC patients, as it can provide predictions about advantages of immunotherapy in HCC patients. The mutation in CTNNB1 and abnormal activation of $\mathrm{Wnt} / \beta$-catenin signaling reduce response of HCC patients to immune checkpoint inhibitors. ${ }^{78}$ Hence, two conclusions can be made, first, $\beta$ catenin mutation should be highlighted based on region and race; second, most of the experiments demonstrated oncogenic role of $\beta$-catenin mutation in HCC. ${ }^{79-84}$

\section{Beta-Catenin and Cancer Stem Cells}

Cancer stem cells (CSCs), also known as tumor-initiating cells, share similar features with normal stem cells, including self-renewal and differentiation capacities. ${ }^{85,86} \mathrm{CSCs}$

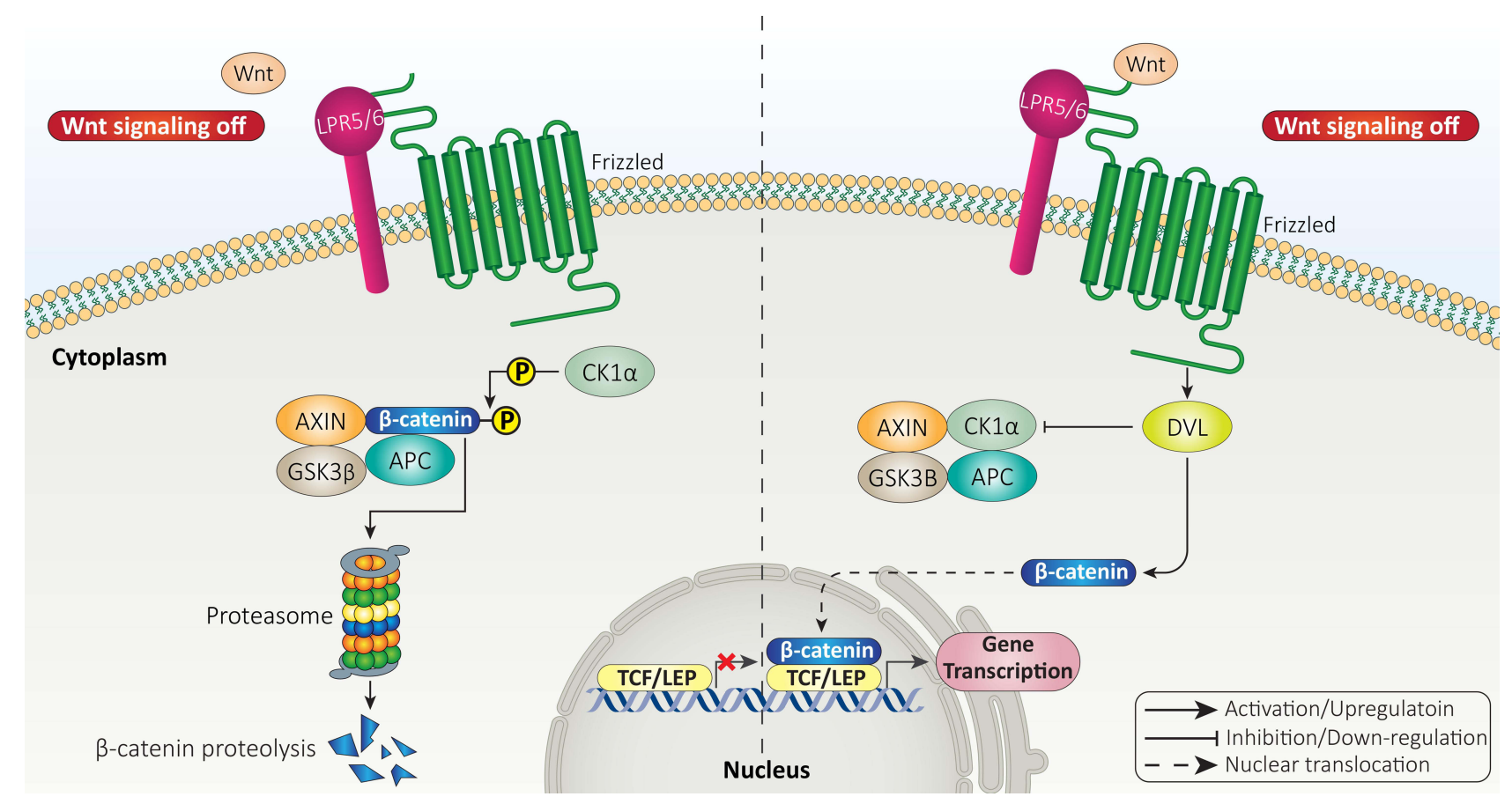

Figure I The canonical pathway of Wnt signaling. 
were first identified in acute myeloid leukemia and it was found that they can increase number of colony-formation capacitors. ${ }^{87} \mathrm{CSCs}$ are responsible for developing heterogenous feature of tumors and is in contrast with conventional belief that tumor heterogeneity is mediated by genetic and epigenetic alterations. ${ }^{88,89} \mathrm{CSCs}$ have been isolated from various tumors including glioma, lung cancer, breast cancer, and liver cancer. ${ }^{90,91}$ CSCs are recognized with a number of cellular markers including CD133, CD44, LGR5 and ALDH1, among others. ${ }^{92}$ The CSCs play a significant role in increasing progression of $\mathrm{HCC}$ cells, and $\beta$-catenin is among the pathways that mediate stemness. Protein tyrosine kinase 2 (PTK2) is considered a tumor-promoting factor in $\mathrm{HCC}$ that enhances viability and survival rate of HCC cells and induces their sorafenib resistance. Furthermore, PTK2 elevates CSC features of HCC via activating Wnt signaling and promoting nuclear translocation of $\beta$-catenin. ${ }^{93}$

The macrophages that infiltrate tumor microenvironment (TME) are known as tumor-associated macrophages (TAMs). ${ }^{94}$ Based on their stimulation by cytokines or chemokines, TAMs are divided into two major kinds, M1 and M2 macrophages. The M1 phenotype macrophages demonstrate tumor-suppressor activity, while M2 phenotype macrophages are able to secrete cytokines to enhance immune evasion, progression and angiogenesis. ${ }^{95,96}$ A recent experiment revealed that M2 phenotype macrophages secrete tumor necrosis factor- $\alpha$ (TNF- $\alpha$ ) that subsequently promotes stemness and EMT in HCC. Investigation of molecular pathways revealed that M2 macrophage-derived TNF- $\alpha$ can induce Wnt/ $\beta$-catenin signaling to promote $\mathrm{CSC}$ characteristics of $\mathrm{HCC}{ }^{97}$ The positive association between $\beta$-catenin and HCC stemness has a clinical implication. It has been reported that increased stemness of HCC, due to $\beta$-catenin, predicts recurrence of this malignant condition. ${ }^{98}$ Therefore, after treatment of $\mathrm{HCC}$ by chemotherapy, radiotherapy or immunotherapy, special attention should be directed toward complete eradication of CSCs in HCC and inhibiting $\beta$-catenin signaling to minimize risk of recurrence.

There is a close association between redox status and Wnt signaling in HCC. It is obvious that enhanced ROS generation can reduce viability of HCC cells via mediating apoptosis. ${ }^{99,100}$ A recent experiment has shed more light on the role of ROS in HCC. It was reported that ROS overgeneration can suppress $\mathrm{Wnt} / \beta$-catenin axis in decreasing survival rate of HCC cells. Glutaminase 1 (GLS1) is suggested to undergo upregulation in $\mathrm{HCC}$ and be correlated with undesirable prognosis. GLS1 mediates clinicopathological characteristic of $\mathrm{HCC}$ and enhances stemness and CSC features. Upon GLS1 overexpression, the levels of stem cell markers such as KFL4, SOX2, Nanog, Oct4 and CD44 undergo an increase in expression. In this way, GLS1 reduces ROS levels to induce Wnt signaling and mediate nuclear translocation of $\beta$-catenin which favors HCC stemness. ${ }^{101}$ As mentioned in the introduction section, GSK-3 $\beta$ is a negative regulator of Wnt signaling and inhibits its activation via mediating proteasomal degradation of $\beta$-catenin. ${ }^{102}$ Recently, a novel pathway was revealed in which GGSK-3 $\beta$ is inhibited to induce Wnt signaling. In this way, secretory clusterin (sCLU) increases expression level of protein kinase-B (Akt) as a tumor-promoting factor in HCC. Then, Akt induces GSk-3 $\beta$ phosphorylation to mediate its proteasomal degradation. Finally, this axis results in nuclear translocation of $\beta$-catenin and subsequent increase in stemness and CSC features of $\mathrm{HCC}$ that are of importance for mediating drug resistance (sorafenib resistance). ${ }^{103}$ The diterpenoid ovatodiolide as anti-cancer agent, inhibits Wnt/ $\beta$-catenin axis to impair CSC features of HCC cells and disrupt their progression. ${ }^{104}$ Therefore, $\beta$-catenin signaling can be considered a novel target in HCC therapy and for reducing its stemness.

The role of ROS in regulating Wnt/ $\beta$-catenin axis has been highlighted in another experiment. Aquaporin-9 (AQP9) shows low expression in CSCs and is able to diminish stemness. In this way, AQP9 induces ROS overgeneration to suppress $\beta$-catenin signaling, leading to a significant decrease in CSC features. ${ }^{105}$ Besides, activation of $\beta$-catenin signaling can mediate transformation of hepatic progenitor cells to CSCs. ${ }^{106}$ Hence, molecular pathways are divided into two major kinds, including tumor-suppressor and tumor-promoting factors that regulate $\beta$-catenin signaling in affecting CSC features of $\mathrm{HCC}$ cells. Future experiments will shed more light on signaling networks regulating $\beta$-catenin signaling in HCC.

\section{Beta-Catenin, Cancer Proliferation, and Migration}

HCC cells have high capacity for proliferation and enhancing their number, mediating their aggressive behavior. ${ }^{107,108}$ Microscopically, HCC demonstrates four distinct kinds of growth profiles including trabecular, pseudoglandular, solid and microtubular. ${ }^{109}$ Various molecular pathways participate in enhancing proliferation rate 
of HCC cells. For instance, COL4A1 is able to induce $\mathrm{FAK} / \mathrm{Src}$ axis in elevating proliferation of $\mathrm{HCC} .^{110}$ Hepatic stellate cells present in HCC can secrete GDF15 in increasing cancer growth. ${ }^{111}$ Oxysophocarpine, as antitumor agent, inhibits STAT3 pathway to impair HCC progression and promotes anti-tumor immunity via mediating $\mathrm{CD} 8+\mathrm{T}$ cell cytotoxicity. ${ }^{112}$ As $\beta$-catenin has a tumor-promoting role, its activation enhances proliferation rate of HCC cells. Spindle and kinetochore-associated protein 2 (SKA2) shows overexpression in $\mathrm{HCC}$ and its silencing significantly diminishes capacity of HCC cells in colony formation and growth. Mechanistically, SKA2 induces phosphorylation of GSK-3 $\beta$ to mediate its degradation, leading to induction of $\beta$-catenin signaling and increased HCC growth. ${ }^{113}$ Identification of factors affecting $\beta$-catenin signaling in HCC is of interest for developing novel therapeutics in the near future. For instance, phosphatidylinositol 4-phosphate adaptor protein 2 (FAPP2) mediates HCC carcinogenesis in vitro and in vivo via inducing $\mathrm{Wnt} / \beta$-catenin axis. Targeting FAPP2 and reducing its expression result in $\beta$-catenin inactivation and reduced HCC progression. ${ }^{114}$ Notably, there have been efforts in discovery of anti-tumor compounds capable of targeting $\beta$-catenin signaling in $\mathrm{HCC}$ therapy. In HCC patients, there is a positive association between EphB4 and $\beta$-catenin expression that promotes cancer progression. It has been reported that homoharringtonine down-regulates EphB4 expression to mediate phosphorylation and degradation of $\beta$-catenin, impairing HCC progression. ${ }^{115}$ The trans-chalcone is another anti-tumor agent that can reduce $\beta$-catenin expression in impairing proliferation of HCC cells. ${ }^{116}$ These examples were provided to show how $\beta$-catenin activation and inactivation can affect survival rate and growth of HCC cells and in the next sections, we specifically discussed targeting $\beta$-catenin with anti-cancer agents in HCC therapy.

Various ligands for Wnt signaling have been identified. A recent experiment has shown that Wnt7b ligand inhibits destruction complex activity (GSK-3 $\beta / \mathrm{APC} / \mathrm{AXN}$ ) to prevent $\beta$-catenin phosphorylation and mediate its nuclear translocation. In the nucleus, $\beta$-catenin increases expression level of Myc and Cyclin D1 to promote cell cycle progression and increase growth of HCC cells. TCP1 can function as upstream mediator of Wnt7b. Reducing TCP1 expression diminishes $\mathrm{Wnt} 7 \mathrm{~b}$ and $\beta$-catenin expressions. Therefore, overexpression of TCP1 is vital for $\beta$-catenin activation and increasing proliferation rate of $\mathrm{HCC}$ cells. $^{117}$
USP9X is a deubiquitinating enzyme evolutionary conserved from Drosophila to humans. ${ }^{118,119}$ The protein transportation, apoptosis, autophagy, cell growth and invasion are among biological mechanisms modulated by USP9X. ${ }^{120-122}$ Recently, attention has been directed toward the role of USP9X in tumor cells. Overexpression of USP9X leads to cisplatin resistance of cancers and its suppression promotes drug sensitivity via inactivating $\beta$ catenin signaling. ${ }^{123}$ There is also a close association between USP9X and $\beta$-catenin in HCC. USP9X enhances proliferation of HCC cells and is correlated with undesirable prognosis. At molecular level, USP9X induces $\beta$ catenin signaling to mediate $\mathrm{HCC}$ progression. ${ }^{124}$ Therefore, mediating GSK-3 $\beta$ degradation and triggering $\beta$-catenin nuclear translocation can significantly enhance proliferation rate of HCC cells. ${ }^{125}$ Besides, activation of $\beta$ catenin signaling induces resistance of HCC cells toward apoptosis. ${ }^{126}$ Histone deacetylase 6 (HDAC6) acts as tumor-suppressor and diminishes $\beta$-catenin expression to induce apoptosis in HCC cells. ${ }^{127}$ In addition to apoptosis, another programmed cell death mechanism, known as autophagy, is affected by $\beta$-catenin signaling in HCC. Briefly, autophagy is induced in cells to preserve homeostasis via degrading toxic and aged macromolecules and organelles. The autophagy function in cancer is controversial and no absolute recommendation can be made about activating or inactivating autophagy, as it has both tumorsuppressor and tumor-promoting roles. ${ }^{128-130} \mathrm{~A}$ recent experiment has shown that autophagy induction enhances proliferation rate of $\mathrm{HCC}$ cells and mediates glycolysis. In this way, autophagy stimulates $\beta$-catenin signaling to increase expression level of monocarboxylate transporter 1 (MCT1), resulting in glycolysis-mediated $\mathrm{HCC}$ growth. ${ }^{131}$ In this case, autophagy plays a tumorpromoting role and its inhibition impairs growth of HCC cells. An experiment has designed FH535 as a small molecule inhibitor of Wnt signaling. Exposing HCC cells to FH535 inhibits $\beta$-catenin to impair autophagy flux, leading to reduced HCC growth. ${ }^{132}$ Overall, $\beta$-catenin is an oncogenic signaling in $\mathrm{HCC}$ and various signaling networks regulate its expression and nuclear translocation that can be the focus of future experiments (Figure 2).

The migration of HCC to distant organs is a complicated process and a variety of molecular pathways can regulate it, and $\beta$-catenin is one among them. The mutations and amplifications in genes are responsible for uncontrolled proliferation of HCC cells which was discussed in the previous section. When HCC cells grow, 


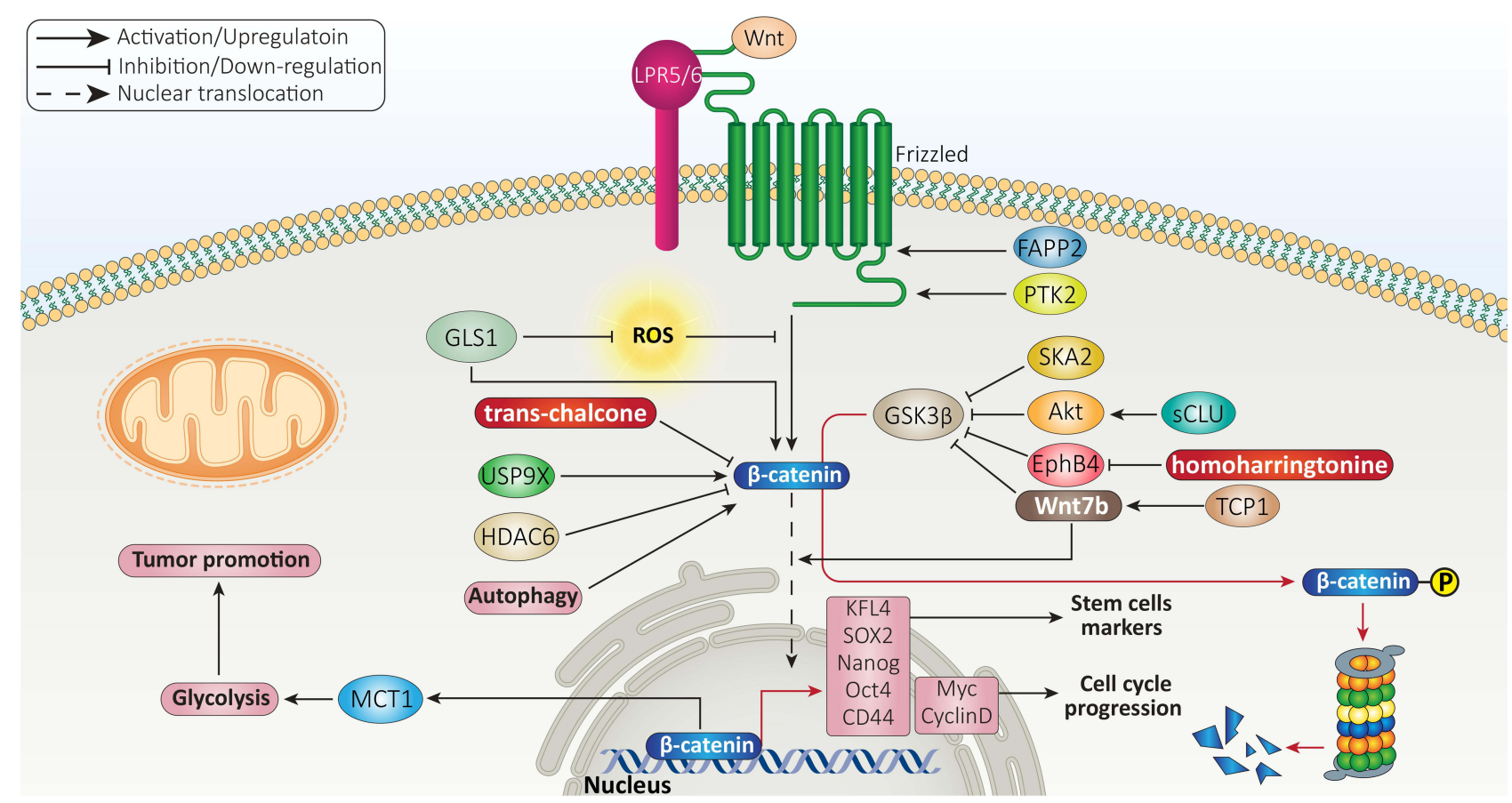

Figure $2 \beta$-catenin association with stemness and proliferation rate of HCC cells.

they require a large amount of energy. Therefore, new vessels are formed to meet needs of HCC cells for energy. The HCC cells are able to degrade basement membrane to enhance their invasion and enter into circulatory system. In the blood circulation, the HCC cells should be able to escape immune surveillance and upon reaching new site, they colonize and new TME provides condition for rapid proliferation of $\mathrm{HCC}$ cells. ${ }^{133,134} \beta$-catenin signaling enhances metastasis of HCC cells via upregulating pyruvate dehydrogenase kinase isoenzyme 1 (PDK1) to stimulate Warburg effect. As a tumor-suppressor, PARP $\gamma$ coactivator- $1 \alpha(\mathrm{PGC}-1 \alpha)$ suppresses $\mathrm{Wnt} / \beta$-catenin axis via upregulating PARP $\gamma$ to impair PDK1 activation and suppress Warburg effect, leading to decreased HCC metastasis. ${ }^{135}$ This experiment correlated Warburg effect and metastasis of HCC cells. However, Warburg effect is related to growth and glycolysis of HCC cells and if the authors have associated it with migration, it may be related to angiogenesis induction after Warburg effect to meet needs of HCC cells for energy. Therefore, more experiments should be performed in this case to highlight the relationship between Warburg effect and metastasis in $\mathrm{HCC}$ and role of $\beta$-catenin signaling.

Akt can function as upstream mediator of GSK-3 $\beta$ in cancers. For instance, Akt induces $\beta$-catenin signaling via down-regulating GSK-3 $\beta$ to enhance pancreatic cancer progression and induce drug resistance. ${ }^{136}$ The same phenomenon also occurs in HCC, so galectin-3 increases migratory ability of $\mathrm{HCC}$ cells via inducing $\beta$-catenin signaling. In this way, galectin-3 induces phosphoinositide 3-kinase ( $\mathrm{PI} 3 \mathrm{~K}) / \mathrm{Akt}$ axis to stimulate $\beta$-catenin signaling via mediating GSK-3 $\beta$ degradation. Then, $\beta$-catenin interacts with TCF4 in nucleus to enhance expression level of IGFBP3, leading to angiogenesis and EMT in HCC. ${ }^{137}$

The most well-known factor responsible for enhancing migration and invasion of HCC cells, is EMT. Briefly, EMT is induced by EMT-inducing transcription factors (EMT-TFs) such as ZEB proteins (ZEB1/2), Snail, Slug and TGF- $\beta .{ }^{138,139}$ Furthermore, EMT is characterized by enhanced levels of vimentin and N-cadherin, and decreased levels of E-cadherin. ${ }^{140}$ The induction of EMT in HCC significantly promotes metastasis and is mediated by various molecular pathways including miRNAs, SSR2 and ID1. ${ }^{141-144}$ Recent experiments have shed some light on the association between $\beta$-catenin signaling and EMT in HCC cells. The trans-activation response DNA-binding protein of $43 \mathrm{kDa}$ (TDP-43) is suggested to suppress translation of GSK-3 $\beta$ to induce Wnt/ $\beta$-catenin axis. Then, $\beta$-catenin stimulates EMT and significantly enhances migration of HCC cells. ${ }^{145}$ The molecular pathways that induce EMT are associated with unfavorable prognosis. For instance, ATP-citrate lyase (ACLY) shows 
overexpression in HCC and is corelated with undesirable prognosis. ACLY induces canonical pathway of Wnt by mediating acetylation of $\beta$-catenin on Lys49, resulting in EMT-mediated metastasis of HCC cells. ${ }^{146}$ The reduction of E-cadherin levels and enhanced vimentin and $\mathrm{N}$-cadherin levels are mediated by $\beta$-catenin signaling in triggering EMT in HCC. ${ }^{147}$ Noteworthy, $\beta$-catenin can also affect EMT-TFs in mediating EMT in HCC cells. Rho guanine nucleotide exchange factor 11 (ARHGEF11) stimulates nuclear translocation of $\beta$-catenin to enhance expression level of ZEB1, resulting in EMT induction and enhanced metastasis of HCC cells. ${ }^{148}$ Furthermore, $\mathrm{PI} 3 \mathrm{~K} / \mathrm{Akt}$ signaling mediates nuclear translocation of $\beta$ catenin via mediating GSK-3 $\beta$ degradation, resulting in Snail overexpression and EMT induction in HCC. Silencing PI3K/Akt axis results in GSK-3 $\beta$ overexpression, subsequent inhibition of $\beta$-catenin and prevents Snail/EMT in HCC. ${ }^{149}$ Overall, increasing evidence has revealed a positive association of $\beta$-catenin with HCC metastasis and its capacity in triggering EMT.

In addition to EMT, matrix metalloproteinases (MMPs) also participate in increasing migration and invasion of cancer cells. Overall, MMPs are endopeptidases and their aberrant expression is observed in a variety of diseases including inflammation, fibrosis, tumors, and arthritis. ${ }^{150}$ The expression level of MMPs can be modulated at translational, transcriptional and post-transcriptional levels. Tissue inhibitors of MMPs (TIMPs) are considered suppressors of MMPs in cells. ${ }^{150,151} \beta$-catenin signaling shows interaction with MMPs in HCC that tightly regulates metastasis of these cells. MMP-9 is a target of $\beta$ catenin signaling that mediates progression of HCC cells. Furthermore, $\beta$-catenin induces EMT in promoting progression of HCC. As an anti-cancer agent, arctigenin suppresses Wnt/ $\beta$-catenin axis and enhances GSK-3 $\beta$ expression to inhibit EMT in HCC and reduce MMP-9 expression in impairing migration. ${ }^{152} \mathrm{MMP}-7$ is another factor that undergoes upregulation by $\beta$-catenin signaling to mediate HCC metastasis and migration. The administration of bufalin results in inhibiting phosphorylation of GSK-3 $\beta$ at Ser9 residue, leading to $\beta$-catenin degradation, suppressed Wnt signaling, down-regulatied MMP-7 expression and subsequent decrease in migration and invasion of HCC cells. ${ }^{153}$ In fact, activation of Wnt signaling and nuclear translocation of $\beta$-catenin are necessary for enhancing MMP expression and triggering HCC migration. A recent experiment has shown function of $\mathrm{FBXO17}$ as a tumor-promoting factor in HCC. FBXO17 mediates nuclear translocation of $\beta$-catenin via down-regulating GSK-3 $\beta$ to increase expression level of its target genes including MMP-2 and MMP-9, resulting in HCC metastasis (Figure 3). ${ }^{154}$

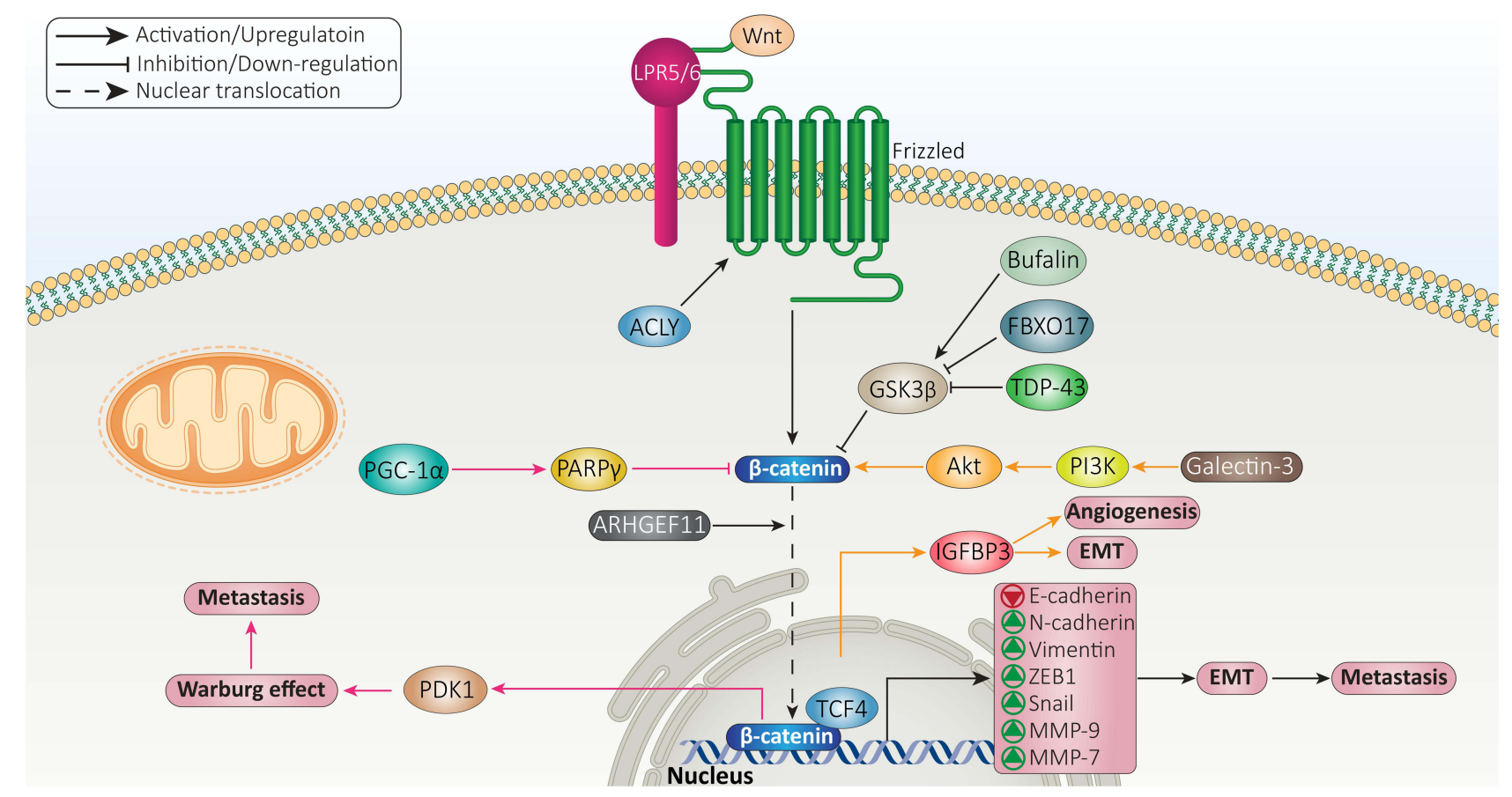

Figure $3 \beta$-catenin signaling in regulation of HCC metastasis. 


\section{Beta-Catenin and Therapy Response}

In respect to role of $\beta$-catenin in mediating resistance feature to various therapies, this section focused on revealing $\beta$-catenin interaction with other molecular pathways in immune and drug resistance. The mutation in CTNNB1 gene encoding $\beta$-catenin mediates low infiltration of cytotoxic immune cells at tumor microenvironment and poor clinical response of HCC cells to immunotherapy. ${ }^{155}$ The suppression of $\beta$-catenin signaling along with anti-PD-1 therapy can exert a synergistic impact on HCC therapy. For this purpose, small interfering RNA (siRNA) was loaded on extracellular vesicles (EVs) as nanoparticles to mediate targeted delivery of siRNA, leading to downregulation of $\beta$-catenin and subsequent enhancement in capacity of anti-PD-1 immunotherapy. ${ }^{156}$ In HCC cells that are resistant to anti-tumor immunity, increasing expression level of CCL5 promotes immune surveillance and prevents immune escape caused by $\beta$-catenin signaling. The HCC cells that demonstrate high expression level of $\beta$-catenin are resistant to anti-PD-1 therapies. In mediating immune evasion feature of HCC cells, $\beta$-catenin signaling impairs recruitment of dendritic cells and decreases activity of $\mathrm{T}$ cells. ${ }^{157}$ These studies highlight the role of $\beta$-catenin signaling in triggering immune evasion in HCC cells and subsequent strategies should focus on suppressing $\beta$-catenin expression in increasing antitumor immunity.

The participation of $\beta$-catenin signaling in chemoresistance feature of HCC cells is complex. The first reason is that a wide variety of molecular pathways have been recognized as upstream and downstream targets of $\beta$ catenin in mediating drug resistance, and second, $\beta$ catenin targets various mechanisms in HCC cells such as their metabolism, proliferation and migration to affect their response to chemotherapy. For instance, gankyrin is suggested to induce metabolic reprogramming of HCC cells to enhance carcinogenesis and mediate their migration and invasion. The underlying molecular pathway is overexpression of $\beta$-catenin by gankyrin that subsequently induces c-Myc signaling in triggering drug resistance. ${ }^{158}$ The stimulation of $\mathrm{Wnt} / \beta$-catenin axis was observed in $14.4 \%$ of HCC patients in a cohort study. The HCC patients with high expression level of $\beta$-catenin showed undesirable prognosis, confirming clinical association of Wnt signaling. Further investigation revealed that activation of $\beta$-catenin signaling by Akt leads to development of a subpopulation of cells with stem cell features and high expression of CD44 that mediate chemoresistance. ${ }^{159}$ Therefore, $\beta$-catenin can affect both metabolism and stem cell features of HCC cells in exerting their resistance to chemotherapy.

The upstream molecular pathways that can enhance stability of $\beta$-catenin are associated with drug resistance in HCC. Nek2 is considered a tumor-promoting factor in $\mathrm{HCC}$ and its overexpression prevents ubiquitination of $\beta$ catenin to increase its stability, leading to sorafenib resistance. Silencing Nek2 in xenograft tumor results in $\beta$ catenin inhibition and subsequent sorafenib sensitivity. ${ }^{160}$ As drug resistance is an increasing challenge in $\mathrm{HCC}$, experiments have focused on combination therapy. A combination of sorafenib $(10 \mathrm{mg} / \mathrm{kg})$ and refametinib (15 mg/kg) synergistically suppressed tumor growth in vivo (xenografts) and impaired proliferation of HCC cells that are attributed to suppressing $\mathrm{Wnt} / \beta$-catenin axis. ${ }^{161}$ Previously, it was mentioned that $\beta$-catenin signaling activation leads to enhanced CSC features in HCC. CDK1 increases PDK1 expression to induce $\beta$-catenin signaling which favors HCC progression. CDK1 overexpression is observed in $46 \%$ of HCC cases and is correlated with undesirable prognosis. The CDK1/PDK1/ $\beta$ catenin axis increases CSC characteristics of HCC cells via upregulating Oct4, SOX2 and Nanog. Besides, this axis increases HCC migration via EMT induction and mediates cell cycle progression. As a CDK1 inhibitor, RO3306 down-regulates PDK1 expression to inhibit $\beta$ catenin signaling, leading to sorafenib sensitivity of HCC cells via EMT inhibition, decreased CSC features and impairing cell cycle progression (inhibiting $\mathrm{S}$ phase progression and enhancing number of cells in Sub-G1 phase). ${ }^{162}$ These studies clearly demonstrate association between $\beta$-catenin and CSC feature, migration, proliferation, metabolism and cell cycle regulators in $\mathrm{HCC}$ in affecting therapy response.

Prospero-related homeobox 1 (PROX1) is a modulator of developmental and biological processes ${ }^{163}$ and recently its role in cancer has been highlighted. The overexpression of PROX1 leads to enhanced migration and invasion of HCC cells via hypoxia inducible factor- $1 \alpha$ (HIF-1 $\alpha$ ) upregulation. ${ }^{164}$ Notably, PROX1 can be involved in mediating sorafenib resistance of HCC cells. PROX1 elevates expression level of $\beta$-catenin by binding to its promoter and triggers its nuclear translocation which favors increasing HCC growth and progression, resulting in sorafenib resistance. ${ }^{165}$ The anti-tumor compounds that promote drug sensitivity of $\mathrm{HCC}$ cells are able to affect $\beta$-catenin 
signaling. The interaction between $\beta$-catenin and TCF in nucleus is of importance for increasing expression levels of ZEB1, c-Myc and cyclin D1 to induce EMT in HCC cells exposed to doxorubicin (DOX). Salinomycin administration is suggested to be beneficial in enhancing FOXO3a expression to interfere with $\beta$-catenin and TCF interaction, leading to EMT inhibition and increased drug sensitivity of HCC cells. ${ }^{166}$

The previous sections revealed the potential role of $\beta$ catenin in stimulating the growth and metastasis of HCC cells to mediate their drug resistance and in this way, $\beta$ catenin interacts with various signaling networks. The drug efflux transporters are another option that can be considered in HCC. ATP-binding transporters (ABC) are the most well-known factors involved in mediating chemoresistance in HCC and they pump out anti-tumor agents to reduce their intracellular accumulation. ${ }^{167}$ On the other hand, $\beta$-catenin signaling can function as upstream mediator of $\mathrm{ABC}$ transporters. Inhibition of $\beta$-catenin pathway enhances drug sensitivity via $A B C$ transporter downregulation. ${ }^{168}$ In $\mathrm{HCC}$ cells, FZD7 induces Wnt/ $\beta$-catenin signaling to enhance levels of $\mathrm{ABC}$ transporters (ABCB1,
$\mathrm{ABCC} 1$ and $\mathrm{ABCC} 2$ ), resulting in DOX and rhodamine123 resistance. Quercetin administration as anti-tumor agent, inhibits $W n t / \beta$-catenin signaling via FZD7 downregulation to reduce levels of $\mathrm{ABCB} 1, \mathrm{ABCC} 1$ and $\mathrm{ABCC} 2$. Then, an increase occurs in drug sensitivity of HCC cells. ${ }^{169}$ These experiments highlight the potential role of $\beta$-catenin signaling in mediating chemoresistance in HCC, confirmed by in vitro and in vivo experiments (Figure 4). ${ }^{170,171}$ Table 1 summarizes the role of $\beta$-catenin signaling in therapy resistance of HCC cells.

\section{NcRNAs Regulating Beta-Catenin MicroRNAs}

miRNAs can be found in various parts of genome, intragenic and intergenic. These non-coding RNAs (ncRNAs) have 19-24 nucleotides in length and can regulate gene expression at post-transcriptional level. ${ }^{172,173}$ The miRNAs are able to decrease expression level of target gene by binding to $3^{\prime}$-untranslated region (3'-UTR). Sometimes, miRNAs bind to $5^{\prime}$-UTR and increase expression of target genes. ${ }^{174}$ Regardless of their biological function, miRNAs have been implicated in development

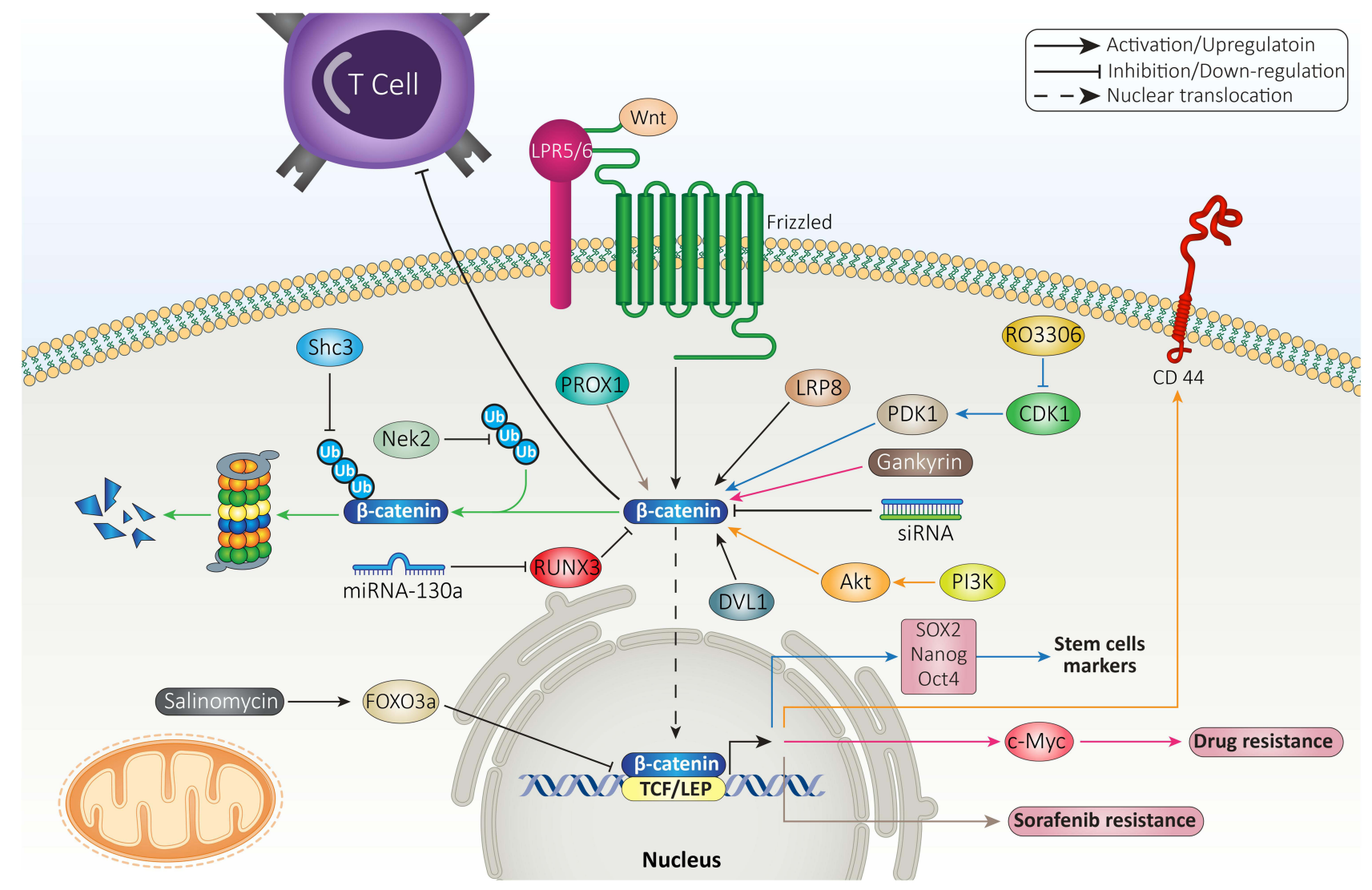

Figure $4 \beta$-catenin signaling determines therapy response of HCC cells. 
Table I The Oncogenic Function of $\beta$-Catenin in Mediating Therapy Resistance of HCC Cells

\begin{tabular}{|c|c|c|c|}
\hline Therapy Resistance & Signaling Network & Remarks & Refs \\
\hline 5-Fluorouracil resistance & DVLI/Wnt & $\begin{array}{l}\text { Overexpression of DVLI in HCC cells } \\
\text { Inducing } \beta \text {-catenin signaling } \\
\text { Triggering drug resistance }\end{array}$ & [269] \\
\hline Sorafenib resistance & LRP8/ $\beta$-catenin & $\begin{array}{l}\text { Overexpression LRP8 in Huh7 cells } \\
\text { Triggering } \beta \text {-catenin signaling } \\
\text { Apoptosis inhibition }\end{array}$ & [270] \\
\hline Cisplatin resistance & miRNA-I30a/RUNX3/Wnt & $\begin{array}{l}\text { Increased expression level of miRNA-I30a } \\
\text { Down-regulating RUNX3 expression } \\
\text { Inducing Wnt/ } 3 \text {-catenin axis } \\
\text { Mediating drug resistance }\end{array}$ & [27I] \\
\hline Immune resistance & $\beta$-catenin & $\begin{array}{l}\text { Triggering immune evasion } \\
\text { Defective recruitment of dendritic cells } \\
\text { Impairing T-cell activity }\end{array}$ & [157] \\
\hline Sorafenib resistance & Gankyrin/ $\beta$-catenin/c-Myc & $\begin{array}{l}\text { Triggering metabolic reprograming } \\
\text { Enhancing growth and metastasis of HCC cells } \\
\text { Inducing } \beta / \text { catenin signaling } \\
\text { Upregulation of c-Myc }\end{array}$ & [158] \\
\hline Sorafenib resistance & PROXI/ $\beta$-catenin & $\begin{array}{l}\text { Increasing proliferation rate of } \mathrm{HCC} \\
\text { Overexpression of PROXI in drug resistant cells } \\
\text { Inducing nuclear translocation of } \beta \text {-catenin }\end{array}$ & [165] \\
\hline Sorafenib and doxorubicin resistance & Shc $3 / \beta$-catenin & $\begin{array}{l}\text { Increasing stemness feature of cancer cells } \\
\text { Enhanced expression of Shc } 3 \\
\text { Inhibiting proteasomal degradation of } \beta \text {-catenin }\end{array}$ & [272] \\
\hline
\end{tabular}

Abbreviations: DVLI, disheveled-I; LRP8, low density lipoprotein receptor-related protein 8; miRNA, microRNA; RUNX3, Runt-related transcription factor 3; HCC, hepatocellular carcinoma; PROXI, Prospero homeobox I.

of various diseases. The aberrant expression of miRNAs occurs in cancers and in this case, miRNAs are divided into two groups including tumor-promoting and tumorsuppressor ones. ${ }^{174}$ Recently, attention has been directed toward the role of miRNAs in HCC as biomarkers and how their expression profile undergoes alterations. The tumor-suppressor miRNAs reduce expression level of $\beta$ catenin by binding to its 3 -UTR. ${ }^{175}$ The expression level of miRNAs with anti-tumor activity significantly diminishes in HCC tissues. The USP22 increases growth and metastasis of HCC cells via inducing Wnt/ $\beta$-catenin signaling. Mechanistically, miRNA-329-3p reduces USP2 2 expression to suppress $\beta$-catenin signaling and improve prognosis of HCC. ${ }^{176}$ These two experiments revealed that miRNAs can affect $\beta$-catenin signaling in HCC in two ways by directly binding to $3^{\prime}$-UTR of $\beta$ catenin or affecting its upstream mediators.

miRNA-466 is a new emerging miRNA in HCC with tumor-suppressor activity. miRNA-466 reduces expression level of ROCK2 to impair metastasis of HCC cells. ${ }^{177}$ miRNA-466 stimulates apoptosis and decreases growth capacity of HCC cells via down-regulating metadherin expression. ${ }^{178}$ miRNA-466 can also affect Wnt/ $\beta$-catenin signaling in HCC. Increasing miRNA-466 expression triggers apoptosis and diminishes growth and migration of HCC cells. At molecular level, miRNA-466 decreases FMNL2 expression to inhibit $\beta$-catenin signaling. ${ }^{179}$ Notably, miRNA/ $\beta$-catenin axis can also be affected by anti-tumor agents. A recent has revealed anti-tumor activity of astragaloside IV in HCC therapy. Exposing HCC cells to astragaloside IV $(0-200 \mu \mathrm{g} / \mathrm{mL})$ increases expression level of miRNA-150-5p to induce apoptosis in HCC cells. Then, overexpressed miRNA-150-5p binds to $3^{\prime}-$ UTR of CTNNB1 to inhibit $\beta$-catenin. ${ }^{180}$

miRNA-26b is another tumor-suppressor factor in HCC. Increasing evidence has revealed the role of miRNA-26b in decreasing HCC growth and metastasis, increasing anti-tumor immunity, and suppressing 
angiogenesis. $^{181-183}$ Zinc ribbon domain-containing 1 (ZNRD1) is suggested to enhance progression of $\mathrm{HCC}$ in vitro and in vivo via inducing $\beta$-catenin signaling. miRNA-26b overexpression reduces ZNRD1 expression to impair Wnt/ $\beta$-catenin axis, reducing growth and metastasis of HCC cells. ${ }^{184}$ miRNA-342 and miRNA-186 can suppress $\beta$-catenin signaling via reducing expression levels of CXCL12 and MCRS1, respectively to impair $\mathrm{HCC}$ progression. $^{185,186}$

On the other hand, there are tumor-promoting miRNAs that significantly enhance HCC progression. For increasing HCC progression, miRNAs can affect upstream mediators of $\beta$-catenin that reduce its expression. SOX transcription factors are able to regulate various molecular pathways in cancer and they possess both tumorsuppressor and tumor-promoting functions. ${ }^{187-190}$ A recent experiment has shown that miRNA-19a-3p and miRNA-376c-3p can elevate progression of HCC cells via reducing SOX6 expression to induce $\mathrm{Wnt} / \beta$-catenin signaling. ${ }^{191}$ Furthermore, there are feedback loops that can regulate expression level of miRNAs targeting $\beta$ catenin signaling. The upregulation of miRNA-5188 is correlated with undesirable prognosis of HCC patients and its targeting (inhibition) can promote sensitivity of cancer cells to chemotherapy. Hepatitis X protein (HBX) is suggested to enhance expression level of miRNA-5188 in HCC. Then, overexpressed miRNA-5188 downregulates FOXO1 expression to induce $\mathrm{Wnt} / \beta$-catenin signaling, leading to EMT induction and c-Jun overexpression. Due to the presence of positive feedback loop, upregulated c-Jun also enhances miRNA-5188 expression to accelerate HCC progression. ${ }^{192}$ The miRNA/ $\beta$-catenin axis can significantly enhance growth and migration of HCC cells. miRNA-629-5p binds to 3'-UTR of secreted frizzled-related protein-2 (SFRP2) to diminish its expression. Then, $\beta$-catenin activation occurs and promotes both growth and migration of HCC cells. ${ }^{193}$ The miRNA/ $\beta$ catenin axis can be attributed to EMT induction and increasing HCC metastasis. ${ }^{194}$ The capacity of miRNA/ $\beta$ catenin axis in increasing HCC growth can be related to upregulating c-Myc and cyclin D1 expressions. ${ }^{195}$

In the previous section, it was discussed that Akt can function as upstream mediator of $\beta$-catenin signaling and induce its overexpression. miRNA-96 shows upregulation in HCC, while FOXO1 undergoes down-regulation, demonstrating their tumor-promoting and tumor-suppressor functions, respectively. FOXO1 inhibition by miRNA-96 significantly enhances growth rate and migration of $\mathrm{HCC}$ cells. By FOXO1 down-regulation, miRNA-96 induces Akt phosphorylation to inhibit GSK-3 $\beta$ activity, resulting in nuclear translocation of $\beta$-catenin. ${ }^{196}$ Another experiment revealed a novel pathway affected by miRNAs in enhancing HCC progression. ST7L is suggested to interact with carboxy terminal region of Akt to reduce its expression. miRNA-23b, as tumor-promoting factor, diminishes ST7L expression to induce Akt signaling, leading to GSK-3 $\beta$ inhibition and subsequent $\beta$-catenin-mediated HCC progression. ${ }^{197}$ For activating $\beta$-catenin signaling, miRNA500 a can directly bind to 3 -UTR of GSK-3 $\beta$ to reduce its expression. ${ }^{198}$ Therefore, the following key points can be concluded:

1. the miRNAs are divided into two groups capable of inhibiting or inducing $\beta$-catenin signaling,

2 . the miRNAs can directly bind to $\beta$-catenin,

3. upstream mediators of $\beta$-catenin such as FOXO1 and GSK-3 $\beta$ can be affected by miRNAs to indirectly target $\beta$-catenin signaling,

4. anti-tumor compounds can affect miRNA/ $\beta$-catenin axis,

5. the miRNA/ $\beta$-catenin axis modulates growth, migration, and drug sensitivity of HCC cells.

\section{Long Non-Coding RNAs}

Although it was first believed that lncRNAs are biologically inactive, these ncRNAs can modulate gene expression at transcription, post-transcriptional, and chromatin levels and have more than 200 nucleotides. ${ }^{199,200}$ DNA methylation, histone modification and chromatin remodeling are affected by $\operatorname{lncRNAs}$ at epigenetic level. ${ }^{201,202}$ Interaction of IncRNAs with DNA or transcriptional factors mediates IncRNA function at transcriptional level. ${ }^{203,204}$ At post-transcriptional level, lncRNAs interact with proteins or mRNA. Recently, lncRNAs have been under noticed in cancer and they can affect growth, invasion, and therapy response of tumor cells. ${ }^{172,205}$ lncRNAs possess valuable functions in HCC. For instance, lncRNA NBR2 can inhibit tumor-promoting autophagy in impairing HCC growth. $^{206}$ In contrast, lncRNA SNHG14 diminishes expression level of PTEN to increase HCC cell viability. ${ }^{207}$ Besides, miRNAs can be affected by IncRNAs in HCC. ${ }^{208}$ The current section focused on lncRNA and $\beta$-catenin interaction in HCC. HCC cells secrete Wnt ligands to induce $\beta$-catenin signaling and mediate polarization of macrophages into M2 phenotype. $^{209}$ Besides, differentiation of monocytes to 
macrophages is modulated by $\beta$-catenin signaling. ${ }^{210}$ A recent experiment has evaluated how IncRNA and $\beta$ catenin association can affect macrophage phenotype in HCC cells. LINC00662 is considered a tumor-promoting lncRNA that shows overexpression in HCC and is correlated with undesirable prognosis. As the first step, lncRNA LINC00662 decreases expression levels of miRNA-15a, miRNA-16 and miRNA-107. Then, an increase occurs in secretion of WNT3A to induce $\beta$-catenin signaling, leading to enhanced growth and migration of HCC cells and suppressing apoptosis. In a paracrine manner, LINC00662 stimulates $\beta$-catenin signaling in macrophages to mediate their M2 polarization, enhancing HCC proliferation and migration. ${ }^{211}$ The lncRNA Linc00210 can increase selfrenewal and tumor-initiating capacity of HCC cells via activating $\beta$-catenin signaling. In this way, Linc00210 inhibits CTNNBIP1 to induce $\mathrm{Wnt} / \beta$-catenin signaling and provide its interaction with TCF/LEF complex in nucleus. Knock-down of Linc00210 inhibits HCC progression in vitro and in vivo. ${ }^{212}$ The ligands of $\beta$-catenin signaling are under tight regulation by lncRNAs. The lncRNA FAM83H-AS1 is able to stimulate $\beta$-catenin signaling by increasing WNT1 expression in HCC. ${ }^{213}$

Identification of tumor-promoting lncRNAs targeting $\beta$-catenin signaling in HCC can pave the way to its treatment. EMT induction and apoptosis inhibition are mediated by lncRNA OGFRP1 via inducing Wnt/ $\beta$ catenin signaling in HCC. Silencing OGFRP1 inactivates $\beta$-catenin signaling, impairing cell cycle progression, inducing apoptosis, and suppressing EMT-mediated metastasis of HCC. ${ }^{214}$ IncRNA and miRNA interaction commonly occurs in HCC. The lncRNA ASB16-AS1 functions as tumor-promoting factor and increases growth and migration. miRNA-1827 functions at the opposite side and decreases FZD4 in HCC. ASB16-AS1 diminishes miRNA-1827 expression via sponging to upregulate FZD4, leading to $\beta$-catenin activation and increased HCC progression. ${ }^{215}$ To date, a wide variety of upstream regulators of $\beta$-catenin signaling have been identified. CDK8 and LRP6 are considered inducers of $\beta$-catenin signaling. A recent experiment has revealed that lncRNA DLGAP1AS1 increases expression levels of CDK8 and LRP6 to induce $\beta$-catenin signaling, Then, overexpressed $\beta$-catenin triggers EMT via reducing E-cadherin levels and enhancing vimentin, N-cadherin and Twist levels to promote HCC metastasis. ${ }^{216}$ Therefore, IncRNAs stimulating $\beta$ catenin can significantly increase HCC progression.
On the opposite side, there are tumor-suppressor IncRNAs that prevent $\beta$-catenin signaling activation. PRDX4 is considered an inducer of $\beta$-catenin signaling in HCC to enhance EMT-mediated metastasis. LncRNA TP53TG1 stimulates PRDX4 degradation via mediating its ubiquitination, leading to $\beta$-catenin inactivation and subsequent inhibited EMT. ${ }^{217}$ The lncRNA NEF is another tumor-suppressor factor that minimizes EMT in HCC. For this purpose, NEF interacts with GSK-3 $\beta$ to induce $\beta$ catenin phosphorylation and degradation, resulting in EMT inhibition. ${ }^{218}$ In addition to metastasis, apoptosis is also regulated by $\operatorname{lncRNA} / \beta$-catenin axis in HCC. The IncRNA ANCR shows down-regulation in HCC cells and tissues and it has a negative association with tumor size and lymph node metastasis. Investigation of molecular pathways revealed that ANCR enhances GSK-3 $\beta$ expression to inhibit $\beta$-catenin signaling. Furthermore, ANCR decreases Wntl expression to suppress $\beta$-catenin. These impacts lead to upregulation of Bax and caspase- 3 in triggering apoptosis in HCC. Besides, ANCR inhibits EMT via affecting $\beta$-catenin signaling. ${ }^{219}$ It should be noted that results of one study cannot be similarly translated to other experiments. In fact, it cannot be concluded that when a certain lncRNA suppresses $\beta$-catenin signaling in HCC, it will also inhibit $\beta$-catenin in other cancer types. A recent experiment has shown that lncRNA CASC2c suppresses $\beta$-catenin signaling in $\mathrm{HCC}$ and gastric cancer, while it induces $\beta$-catenin signaling in colorectal cancer. ${ }^{220}$ Overall, the following keynotes can be concluded:

1. most of the studies have focused on tumorpromoting lncRNAs,

2. the miRNAs can be affected by lncRNAs in targeting $\beta$-catenin signaling,

3. although there are experiments showing that lncRNA/ $\beta$-axis affects growth and invasion of HCC cells, there is no study about impact of drug sensitivity that can be the focus of future experiments,

4. finally, miRNAs can be considered as diagnostic and prognostic tools in HCC.

\section{CircRNAs}

CircRNAs are another category of ncRNAs that were first recognized in plant studies. ${ }^{221}$ CircRNAs have low expression in cells and they were first believed to be a result of RNA splicing. ${ }^{222}$ CircRNAs are stable in multiple tissues and body fluids. ${ }^{217,223}$ They lack protein encoding capacity and they have a closed loop structure. ${ }^{224}$ Recent studies 
have revealed the role of circRNAs in HCC. A variety of molecular pathways including miRNAs, Raf1, PDK1 and RAB1A are modulated by circRNAs in HCC. The proliferation and migration of $\mathrm{HCC}$ cells are affected by circRNAs. Furthermore, circRNAs can regulate HCC response to chemotherapy. ${ }^{225}$ The following sections describe how circRNA and $\beta$-catenin interaction can determine HCC progression.

CircRNAs are divided into two types in HCC including tumor-promoting and tumor-suppressor. The most wellknown pathway for affecting $\beta$-catenin signaling by circRNAs in HCC is to target miRNAs. hsa-circRNA -104348 enhances HCC proliferation and migration, and its knock-down sensitizes cancer cells to apoptosis. Mechanistically, stimulation of $\mathrm{Wnt} / \beta$-catenin signaling by circRNA-104348 mediates its carcinogenesis impact in HCC. $^{226}$ circ-DENND4C is suggested to diminish expression level of miRNA-195-5p in HCC. Then, overexpression of transcription factor 4 (TCF4) occurs, resulting in $\beta$-catenin induction and apoptosis inhibition. ${ }^{227}$ As it was mentioned in the introduction section, CTNNB1 gene encodes $\beta$-catenin in HCC. circZFR decreases miRNA-3619-5p expression via sponging to enhance CTNNB1 expression, resulting in Wnt signaling activation. Then, $\beta$-catenin induces EMT to increase migration and invasion of HCC cells. $^{228}$

FZD5 is considered an oncogene in HCC. FZD5 overexpression can occur in an m6A-dependent manner that subsequently induces $\beta$-catenin signaling in increasing HCC progression. ${ }^{229}$ A recent experiment has shown that circ-0067934 down-regulates miRNA-1324 expression to increase FZD5 expression. Next, FZD5 triggers $\beta$-catenin signaling to dually elevate growth and invasion of HCC cells. $^{230}$ Furthermore, $\beta$-catenin signaling induction by circRNA ZNF292 prevents apoptotic cell death and increases cell cycle progression via $\mathrm{S}$ phase. ${ }^{231}$

The previous statements revealed the role of tumorpromoting circRNAs in HCC. Similar to other ncRNAs, experiments have also recognized circRNAs capable of suppressing $\beta$-catenin signaling in HCC. circRNA-ITCH is suggested to decrease expression levels of miRNA-7 and miRNA-214 in suppressing $\beta$-catenin signaling, resulting in apoptosis induction and decreased colony formation capacity. $^{232}$ miRNA-626 induces $\beta$-catenin signaling in HCC via down-regulating DKK3 expression. As tumorsuppressor, hsa-circ-0004018 diminishes miRNA-626 expression to promote DKK3 expression. Then, $\beta$ - signaling inhibition occurs and HCC carcinogenesis is suppressed. $^{233}$

Cisplatin (CP) is a chemotherapeutic agent belonging to platinum compounds, capable of inhibiting DNA function, enhancing reactive oxygen species (ROS) levels and apoptosis induction..$^{234-236}$ One of the challenges in HCC therapy is the emergence of CP resistance, and overexpression of Nrf2 and HIF-1 $\alpha$ can lead to this condition. ${ }^{237}$ The inhibition of PI3K/Akt axis by miRNA-27a-3p results in enhanced CP cytotoxicity against HCC cells. ${ }^{238}$ The expression level of circ-0003418 undergoes downregulation in $\mathrm{HCC}$ cells and tissues. Enhancing cric0003418 expression suppresses $\mathrm{Wnt} / \beta$-catenin axis to increase CP cytotoxicity. ${ }^{210}$ Overall, the following keynotes can be concluded:

1. circRNAs mainly affect miRNAs in targeting $\beta$ catenin signaling.

2. Therapy response and progression of HCC cells are regulated by circRNA/ $\beta$-catenin axis.

Figure 5 and Table 2 demonstrate the role of ncRNAs in regulating $\beta$-signaling in $\mathrm{HCC}$.

\section{Pharmacological Targeting of Beta-Catenin}

Due to the oncogenic role of $\beta$-catenin signaling in $\mathrm{HCC}$, efforts have been made in targeting this pathway. To date, wide varieties of pharmacological compounds have been applied in HCC suppression via targeting different signaling cascades, including $\beta$-catenin signaling. Most of these anti-cancer agents are plant-derived, natural compounds which can modulate cancer progression, ${ }^{239-242}$ and some of them are synthetic agents. As the first step, anti-tumor agents are able to decrease expression level of $\beta$-catenin. Then, Wnt signaling inhibition occurs, leading to a significant reduction in growth and metastasis of HCC cells. $^{243}$ Furthermore, anti-cancer agents can enhance expression level of GSK-3 $\beta$ to induce proteasomal degradation of $\beta$-catenin, resulting in a significant decrease in its cytoplasmic and nuclear levels. ${ }^{244}$ At another stage, anticancer agents can affect upstream mediators of $\beta$-catenin signaling in HCC. For instance, propofol has been suggested to enhance expression level of miRNA-219-5p in impairing growth and migration of HCC cells. As a result, overexpressed miRNA-219-5p decreases glypican-3 expression to suppress $\mathrm{Wnt} / \beta$-catenin signaling. The 


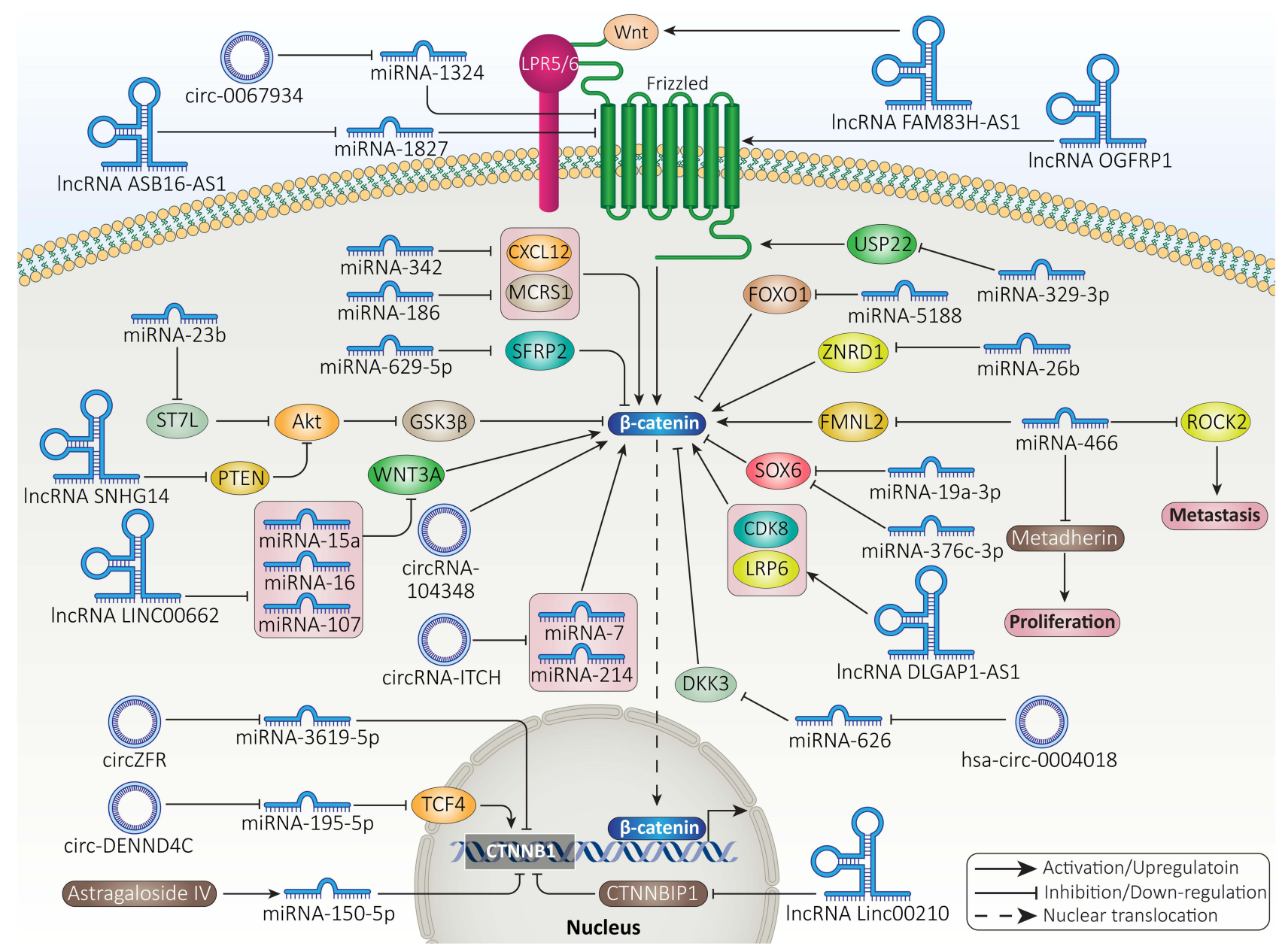

Figure 5 The ncRNAs modulate $\beta$-catenin signaling in $\mathrm{HCC}$.

reduced invasion results from EMT inhibition. ${ }^{245}$ Finally, it has been reported that urolithin B as anti-cancer agent, can inhibit nuclear translocation of $\beta$-catenin signaling in HCC. ${ }^{246}$ Therefore, $\beta$-catenin signaling is affected in four stages including its expression level, GSK-3 $\beta$ upregulation for mediating its degradation and affecting upstream signaling pathways as well as inhibiting its cytoplasm to nuclear translocation.

Sevoflurane (Sevo) is a volatile anesthetic agent that has shown anti-tumor activity via apoptosis induction, triggering cell cycle arrest and metastasis inhibition. ${ }^{247}$ Sevo is able to promote miRNA-29a expression to downregulate Dnmt3a, impairing HCC growth. ${ }^{248}$ In HCC cells, Sevo decreases expression level of miRNA-25-3p to induce PTEN signaling. Then, PTEN inhibits Akt to enhance GSK-3 $\beta$ expression, leading to $\beta$-catenin signaling inhibition and a decrease in expression level of its downstream targets including c-Myc and MMP-9. ${ }^{249}$ In addition to PTEN, MARCH1 can function as regulator of PI3K/Akt signaling in HCC. Exposing HepG2 cells to secalonic acid-F (SAF) is correlated with a significant decrease in MARCH1 expression. Besides, MARCH1 down-regulation by siRNA exerts similar anti-tumor effects. By down-regulation of MARCH1, SAF prevents PI3K/Akt signaling, leading to $\beta$-catenin inhibition and decreased HCC progression. ${ }^{250}$ One of the interesting points is the anti-tumor activity of anesthetic agents. Similar to Sevo, propofol is an anesthetic agent that has been able to inhibit cancer progression via regulating molecular pathways such as miRNAs. ${ }^{26,251,252}$ HMGA2 increases growth and metastasis of HCC cells via inducing Wnt/ $\beta$-catenin signaling. In a concentration-dependent manner, propofol induces apoptosis and disrupts progression of HCC cells. Mechanistically, propofol reduces HMGA2 expression to inhibit Wnt/ $\beta$-catenin signaling. ${ }^{253}$ Therefore, more investigations should be performed in 
Table 2 Non-Coding RNAs Regulating $\beta$-Catenin Signaling in HCC

\begin{tabular}{|c|c|c|c|c|}
\hline NcRNA & Function & Signaling Networks & Remarks & Refs \\
\hline $\begin{array}{l}\text { miRNA-182- } \\
5 p\end{array}$ & $\begin{array}{l}\text { Tumor- } \\
\text { promoting }\end{array}$ & $\mathrm{FOXO3a/ \beta -catenin}$ & $\begin{array}{l}\text { Reducing expression level of FOXO3a } \\
\text { Inhibiting proteasomal degradation of } \beta \text {-catenin } \\
\text { Enhancing } \mathrm{HCC} \text { progression and recurrence }\end{array}$ & [273] \\
\hline miRNA-27a & $\begin{array}{l}\text { Tumor- } \\
\text { promoting }\end{array}$ & B-catenin/EMT & $\begin{array}{l}\text { Enhancing metastasis of } \mathrm{HCC} \text { cells } \\
\text { Inducing } \beta \text {-catenin signaling } \\
\text { Decreasing E-cadherin levels and increasing vimentin levels in triggering EMT in } \\
\mathrm{HCC}\end{array}$ & {$[274]$} \\
\hline miRNA-I 55 & $\begin{array}{l}\text { Tumor- } \\
\text { promoting }\end{array}$ & $\mathrm{PI} 3 \mathrm{~K} / \mathrm{SGK} 3 / \beta$-catenin & $\begin{array}{l}\text { P85 } \alpha \text { suppression by miRNA-I } 55 \text { and increased SGK } 3 \text { expression } \\
\text { Eliminating inhibitory impact of PI3K on SGK3 } \\
\text { Inducing } \beta \text {-catenin signaling } \\
\text { Mediating EMT mechanism }\end{array}$ & {$[275]$} \\
\hline $\begin{array}{l}\text { miRNA-885- } \\
5 p\end{array}$ & $\begin{array}{l}\text { Tumor- } \\
\text { suppressor }\end{array}$ & Wnt/ $\beta$-catenin & $\begin{array}{l}\text { Impairing growth rate of } \mathrm{HCC} \text { cells } \\
\text { Down-regulating expression level of CTNNBI } \\
\text { Suppressing } \beta \text {-catenin signaling }\end{array}$ & {$[276]$} \\
\hline miRNA-I 44 & $\begin{array}{l}\text { Tumor- } \\
\text { suppressor }\end{array}$ & CLK3/ $\beta$-catenin & $\begin{array}{l}\text { Down-regulation of miRNA-I } 44 \text { in HCC and overexpression of CLK3 } \\
\text { Enhancing miRNA-I } 44 \text { expression results in CLK3 down-regulation and } \\
\text { subsequent inhibition of } \beta \text {-catenin signaling }\end{array}$ & {$[250]$} \\
\hline miRNA-I30I & $\begin{array}{l}\text { Tumor- } \\
\text { suppressor }\end{array}$ & BCL9/Wnt/ $\beta$-catenin & $\begin{array}{l}\text { Suppressing angiogenesis, EMT and proliferation of HCC cells } \\
\text { BCL9 down-regulation and subsequent inhibition of } \beta \text {-catenin signaling }\end{array}$ & [277] \\
\hline miRNA- 122 & $\begin{array}{l}\text { Tumor- } \\
\text { suppressor }\end{array}$ & Wnt/B-catenin/MDRI & $\begin{array}{l}\text { Apoptosis induction } \\
\text { Increasing sensitivity of cancer cells to oxaliplatin chemotherapy } \\
\text { Inhibiting } \beta \text {-catenin signaling to diminish expression level of MDRI }\end{array}$ & [278] \\
\hline miRNA-I 22 & $\begin{array}{l}\text { Tumor- } \\
\text { suppressor }\end{array}$ & $\mathrm{Wnt} / \beta$-catenin & $\begin{array}{l}\text { Disrupting migration and growth of } \mathrm{HCC} \text { cells } \\
\text { Inhibiting } \beta \text {-catenin signaling }\end{array}$ & [279] \\
\hline $\begin{array}{l}\text { LncRNA- } \\
\text { RUNXI }\end{array}$ & $\begin{array}{l}\text { Tumor- } \\
\text { suppressor }\end{array}$ & $\begin{array}{l}\text { miRNA-632/GSK-3 } \beta / \\
\beta \text {-catenin }\end{array}$ & $\begin{array}{l}\text { Reduced miRNA- } 632 \text { expression by RUNXI via ceRNA action } \\
\text { Enhancing GSK- } 3 \beta \text { expression to suppress } \beta \text {-catenin signaling } \\
\text { Impairing growth and invasion of HCC cells }\end{array}$ & {$[280]$} \\
\hline $\begin{array}{l}\text { LncRNA- } \\
\text { MIR22HG }\end{array}$ & $\begin{array}{l}\text { Tumor- } \\
\text { suppressor }\end{array}$ & $\begin{array}{l}\text { miRNA-10a-5p/ } \\
\text { NCOR2/ } \beta \text {-catenin }\end{array}$ & $\begin{array}{l}\text { Reducing miRNA-I0a-5p expression } \\
\text { Increasing NCOR } 2 \text { expression } \\
\text { Inactivating } \beta \text {-catenin signaling }\end{array}$ & {$[28 I]$} \\
\hline $\begin{array}{l}\text { LncRNA- } \\
\text { MUF }\end{array}$ & $\begin{array}{l}\text { Tumor- } \\
\text { promoting }\end{array}$ & $\begin{array}{l}\text { ANXA2/ } \beta \text {-catenin } \\
\text { /EMT }\end{array}$ & $\begin{array}{l}\text { Interaction between MUF and ANXA2 induces } \beta \text {-catenin signaling } \\
\text { Triggering EMT mechanism } \\
\text { Increasing cancer migration and invasion }\end{array}$ & [282] \\
\hline $\begin{array}{l}\text { LncRNA- } \\
\text { AWPPH }\end{array}$ & $\begin{array}{l}\text { Tumor- } \\
\text { promoting }\end{array}$ & Wnt/ $\beta$-catenin & $\begin{array}{l}\text { Increasing } \mathrm{HCC} \text { growth and metastasis } \\
\text { Inducing } \beta \text {-catenin signaling }\end{array}$ & [283] \\
\hline $\begin{array}{l}\text { LncRNA- } \\
\text { CRNDE }\end{array}$ & $\begin{array}{l}\text { Tumor- } \\
\text { promoting }\end{array}$ & $\mathrm{Wnt} / \beta$-catenin/EMT & $\begin{array}{l}\text { Increasing cancer metastasis via activating } \beta \text {-catenin signaling and triggering EMT } \\
\text { mechanism }\end{array}$ & {$[284]$} \\
\hline $\begin{array}{l}\text { LncRNA- } \\
\text { DQ786243 }\end{array}$ & $\begin{array}{l}\text { Tumor- } \\
\text { promoting }\end{array}$ & $\begin{array}{l}\text { miRNA-I5b-5p/ } \\
\text { Wnt3A//3-catenin }\end{array}$ & $\begin{array}{l}\text { Reducing expression level of miRNA-15b-5p } \\
\text { Enhancing Wnt } 3 \mathrm{~A} \text { expression to stimulate } \beta \text {-catenin signaling } \\
\text { Facilitating HCC progression }\end{array}$ & [285] \\
\hline
\end{tabular}

Abbreviations: miRNA, microRNA; IncRNA, long non-coding RNA; FOXO3a, forkhead box O3; HCC, hepatocellular carcinoma; EMT, epithelial-to-mesenchymal

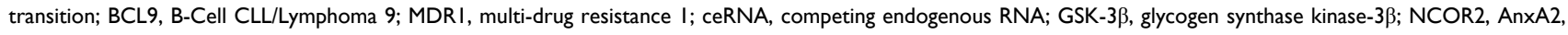
annexin $\mathrm{A} 2$. 
revealing the true potential of anesthetic agents in HCC therapy via targeting $\beta$-catenin signaling.

Berberine is a well-known phytochemical that has recently received attention for its anti-tumor activity. $^{254,255}$ Increasing evidence has revealed the role of berberine in HCC suppression. For instance, berberine increases miRNA-22-3p expression as tumor-suppressor to inhibit $\mathrm{HCC}$ progression. ${ }^{256}$ Besides, berberine prevents inflammation and angiogenesis during non-alcoholic steatohepatitis to inhibit HCC development. ${ }^{257}$ It is suggested that berberine prevents translation of $\beta$-catenin in HCC. In this way, berberine suppresses mTOR signaling to recruit eukaryotic translation initiation factor 4E-binding protein (4E-BP) 1 , leading to $\beta$-catenin translation inhibition. ${ }^{258}$ As $\beta$-catenin increases proliferation rate of HCC cells, its inhibition by pirfenidone leads to sensitizing tumor cells to apoptosis. ${ }^{259}$ Each anti-tumor agent follows a unique pathway in affecting $\beta$-catenin signaling in HCC. For instance, lectin BS-I diminishes sGrp78 and p85 interaction via affecting its membrane localization to inhibit Akt signaling, resulting in GSK-3 $\beta$ overexpression and subsequent inhibition of $\beta$-catenin signaling. ${ }^{260}$ Besides, the benefits of plant-derived, natural compounds is that they can inhibit $\beta$-catenin signaling to induce cytotoxicity against HCC cells, while they are safe and have no toxicity on normal cells or hematological profile. ${ }^{116}$

A few experiments have evaluated synthetic small molecules as inhibitors of $\beta$-catenin signaling. $\mathrm{C}-82$ is a small molecule and active form of PRI-724 that can induce cell cycle arrest at $\mathrm{G} 0 / \mathrm{G} 1$ phase and prevents growth of HCC cells. Besides, C-82 elevates number of cells at sub-G1 phase. C-82 is also able to induce apoptosis in HCC cells. C-82 exerts its tumor-suppressor activity via inhibiting $\beta$-catenin signaling (Figure 6). ${ }^{261}$ Future experiments are suggested to focus on small molecules regulating GSK-3 $\beta$ and also other upstream mediators of $\beta$-catenin signaling, described in aforementioned sections. Table 3 provides an overview of anti-cancer agents targeting $\beta$-catenin signaling in $\mathrm{HCC}$ therapy.

\section{Genetic Intervention in Beta-Catenin Targeting: Prospective and Future Remarks}

The anti-tumor agents that were described in the previous section are able to suppress $\beta$-catenin signaling to effectively inhibit HCC progression. However, these anticancer agents, as most of them are phytochemicals, have problems including low bioavailability and less efficacy

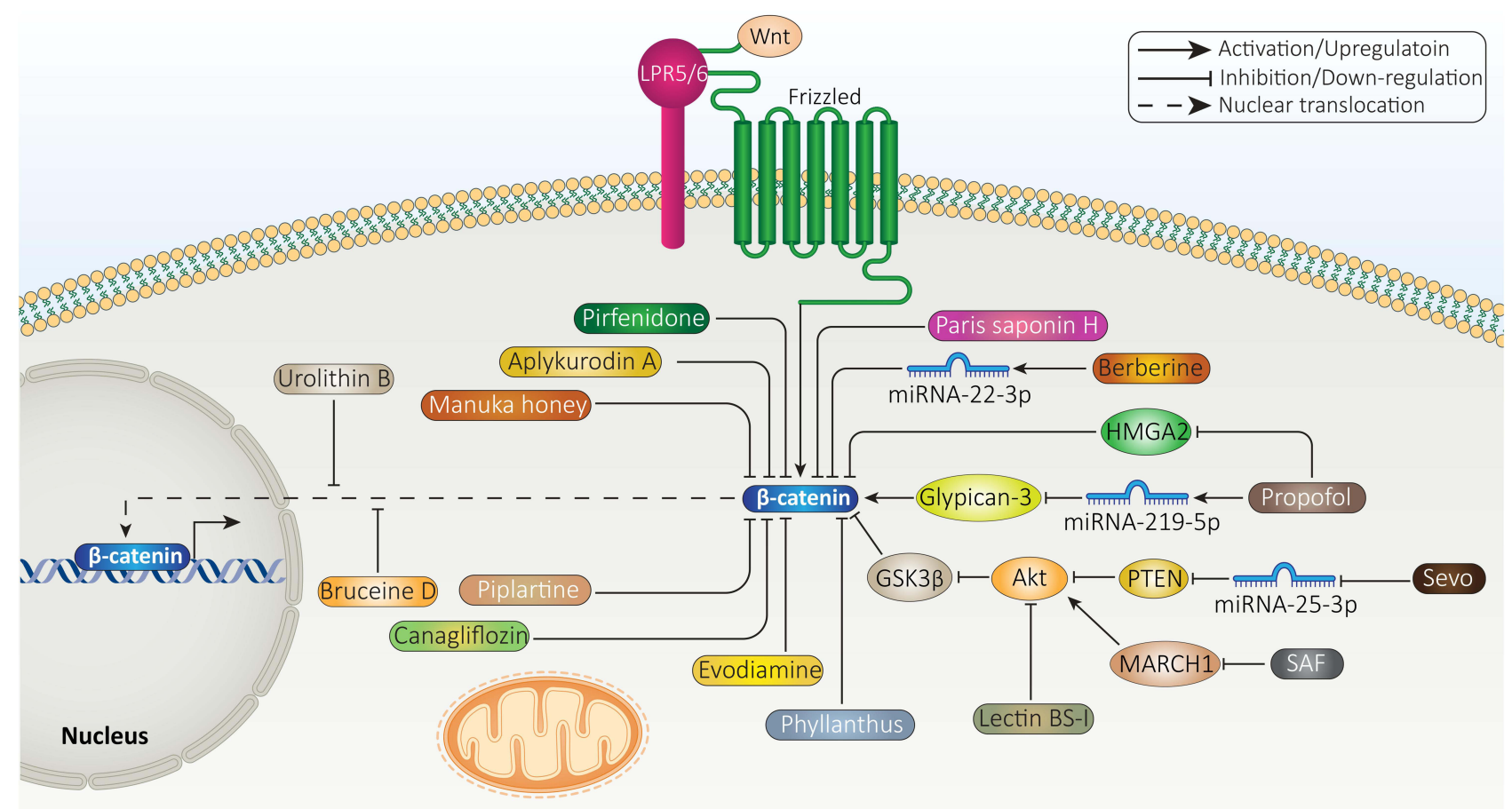

Figure 6 Selected anti-tumor compounds targeting $\beta$-catenin signaling in HCC therapy. 
Table 3 Regulation of $\beta$-Catenin Signaling by Anti-Cancer Agents in HCC Treatment

\begin{tabular}{|c|c|c|c|c|c|}
\hline $\begin{array}{l}\text { Anti-Tumor } \\
\text { Agent }\end{array}$ & $\begin{array}{l}\text { In vitro/ln } \\
\text { vivo }\end{array}$ & $\begin{array}{l}\text { Cell Line/Animal } \\
\text { Model }\end{array}$ & Study Design & Remarks & Refs \\
\hline Aplykurodin A & In vitro & Hep3B and SNU475 cells & 20 and $40 \mu \mathrm{M}$ & $\begin{array}{l}\text { Apoptosis induction } \\
\text { Decreasing proliferation rate of cancer cells } \\
\text { Down-regulating } \beta \text {-catenin expression }\end{array}$ & [286] \\
\hline Manuka honey & In vitro & HepG2 cells & $1.25-20 \% \mathrm{w} / \mathrm{v}$ & $\begin{array}{l}\text { Apoptosis inhibition } \\
\text { Enhancing sensitivity of cancer cells to doxorubicin } \\
\text { Suppressing Wnt/ } \beta \text {-catenin signaling }\end{array}$ & {$[287]$} \\
\hline $\begin{array}{l}\text { Phyllanthus } \\
\text { urinaria L }\end{array}$ & $\begin{array}{l}\text { In vitro } \\
\text { In vivo }\end{array}$ & $\begin{array}{l}\text { HepG2, SMMC-772I, } \\
\text { Huh-7 cells } \\
\text { Xenotransplantation } \\
\text { model }\end{array}$ & $\begin{array}{l}30,60 \text { and } 120 \\
\mu g / \mathrm{mL}\end{array}$ & $\begin{array}{l}\text { Inducing proteasomal degradation of } \beta \text {-catenin via } \\
\text { autophagy inhibition } \\
\text { Impairing metastasis of cancer cells }\end{array}$ & {$[288]$} \\
\hline Piplartine & In vitro & $\begin{array}{l}\text { HepG } 2 \text { and SMMC-772I } \\
\text { cells }\end{array}$ & $\begin{array}{l}0,5,10,15 \text { and } \\
20 \mu \mathrm{M}\end{array}$ & $\begin{array}{l}\text { Suppressing growth and metastasis of HCC cells } \\
\text { Enhancing expression level of LINCOI39I as tumor- } \\
\text { suppressor factor } \\
\text { Subsequent inhibition of } W n t / \beta \text {-catenin axis }\end{array}$ & [289] \\
\hline Canagliflozin & $\begin{array}{l}\text { In vitro } \\
\text { In vivo }\end{array}$ & $\begin{array}{l}\text { Huh7 and Hep3B } \\
\text { Huh7 xenograft tumor } \\
\text { model }\end{array}$ & $\begin{array}{l}0-100 \mu \mathrm{M} \\
300 \mathrm{mg} / \mathrm{kg} / \text { day }\end{array}$ & $\begin{array}{l}\text { Increasing } \beta \text {-catenin phosphorylation to mediate its } \\
\text { proteasomal degradation } \\
\text { Impairing tumor cell growth } \\
\text { Enhancing survival rate of animal models }\end{array}$ & {$[290]$} \\
\hline Evodiamine & $\begin{array}{l}\text { In vitro } \\
\text { In vivo }\end{array}$ & $\begin{array}{l}\text { HepG2, SMMC-772I, and } \\
\text { H22 cells } \\
\text { Nude mice }\end{array}$ & $20 \mathrm{mg} / \mathrm{kg}$ & $\begin{array}{l}\text { Inhibiting } \beta \text {-catenin signaling } \\
\text { Suppressing angiogenesis via down-regulating VEGFa } \\
\text { expression level } \\
\text { Acting as anti-cancer agent }\end{array}$ & {$[291]$} \\
\hline Bruceine D & $\begin{array}{l}\text { In vitro } \\
\text { In vivo }\end{array}$ & $\begin{array}{l}\text { Huh7 and Hep3B HCC } \\
\text { cell lines } \\
\text { HCC xenograft model }\end{array}$ & $\begin{array}{l}0.75 \text { and } 1.5 \mathrm{mg} / \\
\mathrm{kg}\end{array}$ & $\begin{array}{l}\text { Triggering proteasomal degradation of } \beta \text {-catenin } \\
\text { Inhibiting its nuclear translocation } \\
\text { Down-regulation of Jagged I } \\
\text { Suppressing tumor growth }\end{array}$ & [292] \\
\hline $\begin{array}{l}\text { Paris saponin } \\
\mathrm{H}\end{array}$ & $\begin{array}{l}\text { In vitro } \\
\text { In vivo }\end{array}$ & $\begin{array}{l}\text { Huh7 and PLC/PRF/5 } \\
\text { cells } \\
\text { Nude mice }\end{array}$ & $\begin{array}{l}0-20 \mu \mathrm{M} \\
5 \mathrm{mg} / \mathrm{kg}\end{array}$ & $\begin{array}{l}\text { Exerting anti-tumor activity in a dose-dependent manner } \\
\text { EMT inhibition } \\
\text { Reducing } \beta \text {-catenin expression } \\
\text { Inhibiting tumor growth in vitro and in vivo }\end{array}$ & {$[293]$} \\
\hline
\end{tabular}

Abbreviations: VEGF, vascular endothelial growth factor; EMT, epithelial-to-mesenchymal transition; HCC, hepatocellular carcinoma.

in vivo compared to in vivo, showing that they have problems in reaching the tumor site and exerting their antitumor activity. Furthermore, plant-derived natural compounds have multitargeting capacity and along with $\beta$ catenin signaling, they can also affect other molecular pathways. Therefore, in order to be more specific, application of genetic tools in $\beta$-catenin targeting is suggested. Overall, there has been a general overlook toward using genetic tools for specific targeting of $\beta$-catenin signaling in HCC. Most of the experiments have focused on affecting other molecular pathways in context of $\beta$-catenin signaling. Therefore, future experiments should consider $\beta$-catenin targeting in HCC therapy via genetic tools. siRNA is the most well-known genetic tool that can reduce expression of target gene with high application in tumor therapy. ${ }^{262,263}$ A variety of experiments have used siRNA in targeting $\beta$-catenin signaling and providing $\mathrm{HCC}$ treatment. siRNA-CTNBB1 can suppress $\beta$-catenin signaling that in turn, reduces expression level of its target genes such as cyclin D1 and glutamine synthetase in impairing HCC growth. ${ }^{264}$ Upon application of siRNA- $\beta$-catenin, cell cycle arrest at G0/G1 phase occurs. Besides, siRNA- $\beta$ - 
catenin enhances expression levels of Smad3, p-caspase-3 and Grp78, while it diminishes expression levels of TERT, caspase-3, XIAP, MMP-2, MMP-9, VEGF and bFGF protein. The application of siRNA- $\beta$-catenin sensitizes HCC cells to apoptosis. ${ }^{265}$ Short-hairpin RNA (shRNA) and CRISPR/Cas system are other genetic tools that have been applied in treatment of HCC. However, no specific targeting of $\beta$-catenin in these experiments has been performed. Hence, the first limitation is about using genetic tools for specific targeting of $\beta$-catenin. The next limitation is about gene therapy. Similar to anti-tumor compounds, genetic tools have their own drawbacks including off-targeting and degradation by enzymes. Therefore, application of nanostructures for their delivery and increasing their efficacy in cancer suppression is suggested. ${ }^{235,266-268}$ Table 4 summarizes recent efforts in revealing $\beta$-catenin's role in HCC.

\section{Conclusion and Remarks}

In spite of significant advances in HCC management and treatment, there is still a long way to understanding factors responsible for HCC development. HCC has desirable prognosis at early stages, but its advanced stage is resistant to various therapies including immunotherapy,

Table 4 An Overview of $\beta$-Catenin Signaling and Related Molecular Pathways in HCC

\begin{tabular}{|c|c|c|}
\hline Signaling Network & Remarks & Refs \\
\hline CDCA8/Akt/ $/$-catenin & $\begin{array}{l}\text { Acting as tumor-promoting factor and increasing } \mathrm{HCC} \text { progression } \\
\mathrm{CDCA} 8 \text { induces } \mathrm{Akt} / \beta \text {-catenin axis to enhance } \mathrm{HCC} \text { growth } \\
\text { Increasing cancer stemness } \\
\text { Knock-down of CDCA8 impairs HCC proliferation via inhibiting } \beta \text {-catenin }\end{array}$ & [294] \\
\hline UBE2T/Mule/Wnt/ß-catenin & $\begin{array}{l}\text { Overexpression of UBE2T in clinical samples and association with undesirable prognosis } \\
\text { UBE } 2 T \text { interacts with Mule to induce its ubiquitination } \\
\text { Increasing } \beta \text {-catenin stability } \\
\text { Promoting HCC progression }\end{array}$ & [295] \\
\hline sFRP-4/Wnt/B-catenin & $\begin{array}{l}\text { The down-regulation of sFRP- } 4 \text { in } \mathrm{HCC} \\
\text { Suppressing HCC proliferation and inducing apoptosis } \\
\text { Inhibiting } \beta \text {-catenin signaling }\end{array}$ & [296] \\
\hline RAD54B/Wnt/ $\beta$-catenin & $\begin{array}{l}\text { Association with poor prognosis } \\
\text { Enhancing motility and growth of } \mathrm{HCC} \text { cells } \\
\text { Overexpression of RAD54B and inducing } \beta \text {-catenin signaling }\end{array}$ & [297] \\
\hline BAP3I/Akt/ $\beta$-catenin & $\begin{array}{l}\text { Increasing } \mathrm{HCC} \text { metastasis } \\
\text { Upregulation of } \mathrm{BAP} 3 \mathrm{I} \text { and inducing } A \mathrm{kt} / \beta \text {-catenin axis }\end{array}$ & [285] \\
\hline TM2DI/Akt/ $\beta$-catenin & $\begin{array}{l}\text { TM2DI induces EMT to enhance HCC migration and invasion } \\
\text { Stimulating Akt/ } \beta \text {-catenin axis }\end{array}$ & [298] \\
\hline MNSI/PI3K/Akt/ß-catenin & $\begin{array}{l}\text { Association with unfavorable prognosis } \\
\text { Enhancing cancer progression } \\
\text { MNSI induces Akt signaling to enhance nuclear translocation of } \beta \text {-catenin }\end{array}$ & [299] \\
\hline $\begin{array}{l}\beta \text {-catenin/miRNA-22-3p/ } \\
\text { TET2 }\end{array}$ & $\begin{array}{l}\text { Alcohol exposure enhances } \mathrm{HCC} \text { progression } \\
\text { B-catenin elevates miRNA-22-3p expression to down-regulate TET2 expression }\end{array}$ & [300] \\
\hline$\beta$-catenin/KIF2C/mTORCI & $\begin{array}{l}\text { Enhanced expression level of KIF2C by } \beta \text {-catenin } \\
\text { Upregulation of mTORCI } \\
\text { Increasing both growth and invasion of } \mathrm{HCC} \text { cells }\end{array}$ & [301] \\
\hline$\beta$-catenin/NKG2D & $\begin{array}{l}\text { Reduced expression level of NKG2D ligands by } \beta \text {-catenin and association with malignant behavior of HCC } \\
\text { cells }\end{array}$ & [302] \\
\hline Wnt/ $\beta$-catenin & Irradiated mesenchymal stem cells increase stemness of $\mathrm{HCC}$ via inducing $\beta$-catenin signaling & [303] \\
\hline
\end{tabular}

Abbreviations: CDCA8, cell division cycle associated 8; Akt, protein kinase-B; HCC, hepatocellular carcinoma; UBE2T, ubiquitin conjugating enzyme E2 T; sFRP-4, secreted frizzled-related protein 4; PI3K, phosphoinositide 3-kinase; MNSI, Meiosis-specific nuclear structural I; TET2, Tet methylcytosine dioxygenase 2; KIF2c, Kinesin family member 2C; mTORCI, mammalian target of rapamycin complex I; NKG2D, Natural Killer Group 2D. 
chemotherapy, and radiotherapy. HCC cells demonstrate high proliferation and migration rates at advanced stages. Hence, it is vital to identify factors responsible for aggressive behavior of HCC. Increasing evidence has revealed the role of interactions in TME for HCC development and progression. Such interactions promote HCC progression and mediate therapy resistance, threatening life of patients. $\beta$-catenin signaling is an oncogenic pathway that enhances HCC progression via cooperating with other molecular pathways and affecting TME components.

The present review focused on $\beta$-catenin affecting various aspects of HCC. As the first step, $\beta$-catenin signaling increases proliferation rate of HCC cells and prevents apoptosis. Inhibiting $\beta$-catenin signaling promotes expression level of pro-apoptotic factors such as Bax and caspases to induce apoptosis. The cell progression of HCC cells undergoes a significant increase by $\mathrm{Wnt} / \beta$-catenin signaling. Silencing $\mathrm{Wnt} / \beta$-catenin signaling suppresses proliferation rate and cell cycle progression, while it induces apoptosis in HCC cells. To increase growth ability of HCC cells, $\beta$ catenin elevates expression level of tumor-promoting factors such as c-Myc. Besides, $\beta$-catenin enhances stemness of $\mathrm{HCC}$ via improving $\mathrm{CSC}$ features. In addition to growth, $\beta$ catenin signaling increases migration of HCC cells via inducing EMT and promoting expression level of MMPs. Both proliferation and migration rates can be significantly enhanced by $\mathrm{Wnt} / \beta$-catenin signaling and these factors are involved in therapy resistance of HCC cells, thus, knockdown of $\mathrm{Wnt} / \beta$-catenin axis is beneficial in impairing progression and promoting chemosensitivity. Furthermore, $\beta$ catenin signaling can enhance number of macrophages with M2 phenotype in TME to mediate its oncogenic activity in HCC. The macrophages with M1 phenotype suppress HCC progression, while M2 polarization by $\mathrm{Wnt} / \beta$-catenin signaling activation promotes HCC progression. When growth and migration increase, $\mathrm{HCC}$ cells are able to obtain resistance to therapy. $\beta$-catenin-mediated $\mathrm{HCC}$ progression leads to immuno-resistance and drug resistance in HCC. Hence, suppressing $\beta$-catenin signaling can promote therapy response and dually inhibit growth and invasion of HCC cells.

Since Wnt/ $\beta$-catenin signaling activation significantly enhances proliferation and invasion of HCC cells, efforts have been made to target it using different pharmacological strategies. Anti-tumor compounds have been utilized in inhibiting Wnt signaling. Berberine, propofol, sevoflurane, and C-82 as anti-tumor agents are able to inhibit $\mathrm{Wnt} / \beta$ catenin signaling in impairing $\mathrm{HCC}$ progression. On the other hand, siRNA as a nucleic acid drug can inhibit Wnt signaling in reducing $\mathrm{HCC}$ proliferation and invasion. There are upstream mediators of Wnt signaling including miRNAs and lncRNAs that have also been found to regulate HCC progression. Moreover, in addition to the preclinical studies that have shown the role of $\mathrm{Wnt} / \beta$-catenin signaling in HCC progression, clinical studies have also confirmed the role of Wnt overexpression, nuclear translocation of $\beta$-catenin and gene mutation $(C T N B B 1)$ in development and progression of $\mathrm{HCC}$ in patients.

\section{Abbreviations}

PI3K, phosphoinositide 3-kinase; EMT-TFs, EMTinducing transcription factors; TDP-43, trans-activation response DNA-binding protein of 43; ACLY, ATP-citrate lyase; MMPs, matrix metalloproteinases; TIMPs, tissue inhibitors of MMPs; siRNA, small interfering RNA; EVs, extracellular vesicles; PROX1, prospero-related homeobox 1; HIF-1 $\alpha$, hypoxia inducible factor-1 $\alpha$; DOX, doxorubicin; ABC, ATP-binding cassette; HCC, hepatocellular carcinoma; HBV, hepatitis B virus; $\mathrm{HCV}$, hepatitis $\mathrm{C}$ virus; EMT, epithelial-to-mesenchymal transition; S1PR1, sphingosine-1-phosphate receptor-1; lncRNA, long non-coding RNA; miRNAs, microRNAs; circRNAs, circular RNAs; TCF, T cell factor; LEF, lymphoid enhancer factor; CK-1, casein kinase-1; GSK-3 $\beta$, glycogen synthase kinase-3 $\beta$; APC, adenomatous polyposis coli; 5-FU, 5-fluorouracil; PD-L1, programmed death-ligand 1; NK, natural killer; CK19, cytokeratin 19; CSCs, cancer stem cells; PTK2, protein tyrosine kinase 2; TME, tumor microenvironment; TAMs, tumor-associated macrophages; TNF- $\alpha$, tumor necrosis factor- $\alpha$; GLS1, glutaminase 1; sCLU, secretory clusterin; Akt, protein kinase-B; AQP9, aquaporin-9; SKA2, spindle and kinetochore-associated protein 2; FAPP2, phosphatidylinositol 4-phosphate adaptor protein 2; HDAC6, histone deacetylase 6; MCT1, monocarboxylate transporter 1; PDK1, pyruvate dehydrogenase kinase isoenzyme 1; PGC- $1 \alpha, \operatorname{PARP} \alpha$ coactivator$1 \alpha$; ncRNAs, non-coding RNAs; ZNRD1, zinc ribbon domain-containing 1; HBX, hepatitis X protein; SFRP2, secreted frizzled-related protein-2; TCF4, transcription factor 4; CP, cisplatin; ROS, reactive oxygen species; Sevo, sevoflurane; SAF, secalonic acid-F; 4E, BP, 4Ebinding protein; shRNA, short hairpin RNA.

\section{Acknowledgment}

Mahshid Deldar Abad Paskeh and Sepideh Mirzaei participated equally in manuscript preparation. 


\section{Disclosure}

The authors declare no conflicts of interest for this work.

\section{References}

1. Xie DY, Ren ZG, Zhou J, Fan J, Gao Q. 2019 Chinese clinical guidelines for the management of hepatocellular carcinoma: updates and insights. Hepatobiliary Surg Nutr. 2020;9(4):452. doi:10.21037/hbsn-20-480

2. Cui F, Shen L, Li L, et al. Prevention of chronic hepatitis B after 3 decades of escalating vaccination policy, China. Emerg Infect Dis. 2017;23(5):765-772. doi:10.3201/eid2305.161477

3. Huang A, Yang XR, Chung WY, Dennison AR, Zhou J. Targeted therapy for hepatocellular carcinoma. Signal Transduct Target Ther. 2020;5(1):146. doi:10.1038/s41392-020-00264-x

4. Dhanasekaran R, Nault JC, Roberts LR, Zucman-Rossi J. Genomic medicine and implications for hepatocellular carcinoma prevention and therapy. Gastroenterology. 2019;156(2):492-509. doi:10.1053/j.gastro.2018.11.001

5. Llovet JM, Montal R, Sia D, Finn RS. Molecular therapies and precision medicine for hepatocellular carcinoma. Nat Rev Clin Oncol. 2018;15(10):599-616. doi:10.1038/s41571-018-0073-4

6. Swamy SG, Kameshwar VH, Shubha PB, et al. Targeting multiple oncogenic pathways for the treatment of hepatocellular carcinoma. Target Oncol. 2017;12(1):1-10. doi:10.1007/s11523016-0452-7

7. Mastron JK, Siveen KS, Sethi G, Bishayee A. Silymarin and hepatocellular carcinoma: a systematic, comprehensive, and critical review. Anticancer Drugs. 2015;26(5):475-486. doi:10.1097/ cad.0000000000000211

8. Pham C, Fong TL, Zhang J, Liu L. Striking racial/ethnic disparities in liver cancer incidence rates and temporal trends in California, 1988-2012. J Natl Cancer Inst. 2018;110 (11):1259-1269. doi:10.1093/jnci/djy051

9. Prevention of Infection Related Cancer (PIRCA) Group, Specialized Committee of Cancer Prevention and Control, Chinese Preventive Medicine Association; Non-communicable \& Chronic Disease Control and Prevention Society, Chinese Preventive Medicine Association; Health Communication Society, Chinese Preventive Medicine Association. [Strategies of primary prevention of liver cancer in China: expert Consensus (2018)]. Zhonghua Zhong liu Za Zhi. 2018;53(1):36-44. Chinese. doi:10.3760/cma.j.issn.0253-3766.2018.07.013

10. Zhou M, Wang H, Zeng X, et al. Mortality, morbidity, and risk factors in China and its provinces, 1990-2017: a systematic analysis for the Global Burden of Disease Study 2017. Lancet. 2019;394 (10204):1145-1158. doi:10.1016/s0140-6736(19)30427-1

11. Yang JD, Hainaut P, Gores GJ, Amadou A, Plymoth A, Roberts LR. A global view of hepatocellular carcinoma: trends, risk, prevention and management. Nat Rev Gastroenterol Hepatol. 2019;16(10):589-604. doi:10.1038/s41575-019-0186-y

12. Keerthy HK, Mohan CD, Siveen KS, et al. Novel synthetic biscoumarins target tumor necrosis factor- $\alpha$ in hepatocellular carcinoma in vitro and in vivo. $J$ Biol Chem. 2014;289 (46):31879-31890. doi:10.1074/jbc.M114.593855

13. Yang JD, Mannalithara A, Piscitello AJ, et al. Impact of surveillance for hepatocellular carcinoma on survival in patients with compensated cirrhosis. Hepatology. 2018;68(1):78-88. doi:10.1002/hep.29594

14. Pan Y, Chen H, Yu J. Biomarkers in hepatocellular carcinoma: current status and future perspectives. Biomedicines. 2020;8 (12):576. doi:10.3390/biomedicines8120576

15. Jia L, Gao Y, He Y, Hooper JD, Yang P. HBV induced hepatocellular carcinoma and related potential immunotherapy. Pharmacol Res. 2020;159:104992. doi:10.1016/j.phrs.2020.104992
16. Yang P, Markowitz GJ, Wang XF. The hepatitis B virus-associated tumor microenvironment in hepatocellular carcinoma. Natl Sci Rev. 2014;1(3):396-412. doi:10.1093/nsr/ nwu038

17. Tang A, Hallouch O, Chernyak V, Kamaya A, Sirlin CB. Epidemiology of hepatocellular carcinoma: target population for surveillance and diagnosis. Abdom Radiol (NY). 2018;43 (1):13-25. doi:10.1007/s00261-017-1209-1

18. Liang HW, Wang N, Wang Y, et al. Hepatitis B virus-human chimeric transcript HBx-LINE1 promotes hepatic injury via sequestering cellular microRNA-122. J Hepatol. 2016;64 (2):278-291. doi:10.1016/j.jhep.2015.09.013

19. Dai X, Ahn KS, Kim C, et al. Ascochlorin, an isoprenoid antibiotic inhibits growth and invasion of hepatocellular carcinoma by targeting STAT3 signaling cascade through the induction of PIAS3. Mol Oncol. 2015;9(4):818-833. doi:10.1016/j. molonc.2014.12.008

20. Chen X, Tang FR, Arfuso F, et al. The emerging role of long non-coding RNAs in the metastasis of hepatocellular carcinoma. Biomolecules. 2019;10(1):66. doi:10.3390/biom10010066

21. Mohan CD, Rangappa S, Nayak SC, Sethi G, Rangappa KS. Paradoxical functions of long noncoding RNAs in modulating STAT3 signaling pathway in hepatocellular carcinoma. Biochim Biophys Acta Rev Cancer. 2021;1876(1):188574. doi:10.1016/j. bbcan.2021.188574

22. Cheng JT, Wang L, Wang H, et al. Insights into biological role of LncRNAs in epithelial-mesenchymal transition. Cells. 2019;8 (10):1178. doi:10.3390/cells8101178

23. Yokota T, Nojima H, Kuboki S, et al. Sphingosine-1-phosphate Receptor-1 Promotes Vascular Invasion and EMT in Hepatocellular Carcinoma. J Surg Res. 2021;259:200-210. doi:10.1016/j.jss.2020.11.044

24. Ma W, Chen X, Wu X, et al. Long noncoding RNA SPRY4-IT1 promotes proliferation and metastasis of hepatocellular carcinoma via mediating TNF signaling pathway. J Cell Physiol. 2020;235 (11):7849-7862. doi:10.1002/jcp.29438

25. Xiang Y, Liu L, Wang Y, Li B, Peng J, Feng D. ADAM17 promotes the invasion of hepatocellular carcinoma via upregulation MMP21. Cancer Cell Int. 2020;20:516. doi:10.1186/s12935020-01556-6

26. Bashir AO, El-Mesery ME, Anwer R, Eissa LA. Thymoquinone potentiates miR-16 and miR-375 expressions in hepatocellular carcinoma. Life Sci. 2020;254:117794. doi:10.1016/j.1fs.2020.117794

27. Guan Y, Zhang Y, Hao L, Nie Z. CircRNA_102272 promotes cisplatin-resistance in hepatocellular carcinoma by decreasing MiR-326 targeting of RUNX2. Cancer Manag Res. 2020;12:12527-12534. doi:10.2147/cmar.S258230

28. Zhang Z, Tan X, Luo J, Yao H, Si Z, Tong JS. The miR-30a-5p/ CLCF1 axis regulates sorafenib resistance and aerobic glycolysis in hepatocellular carcinoma. Cell Death Dis. 2020;11(10):902. doi:10.1038/s41419-020-03123-3

29. He Q, Lin Z, Wang Z, et al. SIX4 promotes hepatocellular carcinoma metastasis through upregulating YAP1 and c-MET. Oncogene. 2020;39(50):7279-7295. doi:10.1038/s41388-020-01500-y

30. Zheng Y, Huang C, Lu L, et al. STOML2 potentiates metastasis of hepatocellular carcinoma by promoting PINK1-mediated mitophagy and regulates sensitivity to lenvatinib. J Hematol Oncol. 2021;14(1):16. doi:10.1186/s13045-020-01029-3

31. Jiang K, Dong C, Yin Z, et al. Exosome-derived ENO1 regulates integrin $\alpha 6 \beta 4$ expression and promotes hepatocellular carcinoma growth and metastasis. Cell Death Dis. 2020;11(11):972. doi:10.1038/s41419-020-03179-1

32. López-Cánovas JL, Del Rio-Moreno M, García-Fernandez H, et al. Splicing factor SF3B1 is overexpressed and implicated in the aggressiveness and survival of hepatocellular carcinoma. Cancer Lett. 2021;496:72-83. doi:10.1016/j.canlet.2020.10.010 
33. Li L, He K, Chen S, et al. Circ 0001175 promotes hepatocellular carcinoma cell proliferation and metastasis by regulating miR-130a-5p. Onco Targets Ther. 2020;13:13315-13327. doi: $10.2147 /$ ott.S262408

34. Chan LK, Ho DW, Kam CS, et al. RSK2-inactivating mutations potentiate MAPK signaling and support cholesterol metabolism in hepatocellular carcinoma. $J$ Hepatol. 2021;74(2):360-371. doi:10.1016/j.jhep.2020.08.036

35. Hiremath IS, Goel A, Warrier S, Kumar AP, Sethi G, Garg M. The multidimensional role of the $\mathrm{Wnt} / \beta$-catenin signaling pathway in human malignancies. J Cell Physiol. 2021. doi:10.1002/ jcp. 30561

36. Mohan CD, Bharathkumar H, Bulusu KC, et al. Development of a novel azaspirane that targets the Janus kinase-signal transducer and activator of transcription (STAT) pathway in hepatocellular carcinoma in vitro and in vivo. $J$ Biol Chem. 2014;289 (49):34296-34307. doi:10.1074/jbc.M114.601104

37. Tewari D, Nabavi SF, Nabavi SM, et al. Targeting activator protein 1 signaling pathway by bioactive natural agents: possible therapeutic strategy for cancer prevention and intervention. Pharmacol Res. 2018;128:366-375. doi:10.1016/j.phrs.2017. 09.014

38. Chopra P, Sethi G, Dastidar SG, Ray A. Polo-like kinase inhibitors: an emerging opportunity for cancer therapeutics. Expert Opin Investig Drugs. 2010;19(1):27-43. doi:10.1517/ 13543780903483191

39. Wang B, Li X, Liu L, Wang M. $\beta$-Catenin: oncogenic role and therapeutic target in cervical cancer. Biol Res. 2020;53(1):1-11. doi:10.1186/s40659-020-00301-7

40. Morin PJ, Sparks AB, Korinek V, et al. Activation of beta-catenin-Tcf signaling in colon cancer by mutations in beta-catenin or APC. Science. 1997;275(5307):1787-1790. doi:10.1126/science. 275.5307 .1787

41. Xing Y, Takemaru K-I, Liu J, et al. Crystal structure of a fulllength $\beta$-catenin. Structure. 2008;16(3):478-487. doi:10.1016/j. str.2007.12.021

42. Zhang X, Wang L, Qu Y. Targeting the $\beta$-catenin signaling for cancer therapy. Pharmacol Res. 2020;160:104794. doi:10.1016/j. phrs.2020.104794

43. Städeli R, Hoffmans R, Basler K. Transcription under the control of nuclear Arm/beta-catenin. Curr Biol. 2006;16(10):R378-385. doi:10.1016/j.cub.2006.04.019

44. Vleminckx K, Kemler R, Hecht A. The C-terminal transactivation domain of $\beta$-catenin is necessary and sufficient for signaling by the LEF-1/ß-catenin complex in Xenopus laevis. Mech Dev. 1999;81(1-2):65-74. doi:10.1016/S0925-4773(98)00225-1

45. Wang Z, Li Z, Ji H. Direct targeting of $\beta$-catenin in the Wnt signaling pathway: Current progress and perspectives. Med Res Rev. 2021;41(4):2109-2129. doi:10.1002/med.21787

46. Söderholm S, Cantù $C$. The WNT/ $\beta$-catenin dependent transcription: a tissue-specific business. Wiley Interdiscip Rev Syst Biol Med. 2020:e1511. doi:10.1002/wsbm.1511

47. Ong MS, Cai W, Yuan Y, et al. 'Lnc'-ing Wnt in female reproductive cancers: therapeutic potential of long non-coding RNAs in Wnt signalling. Br J Pharmacol. 2017;174(24):4684-4700. doi:10.1111/bph.13958

48. Bhuvanalakshmi G, Gamit N, Patil M, et al. Stemness, Pluripotentiality, and Wnt Antagonism: sFRP4, a Wnt antagonist Mediates Pluripotency and Stemness in Glioblastoma. Cancers (Basel). 2018;11(1):25. doi:10.3390/cancers11010025

49. Peifer M, Rauskolb C, Williams M, Riggleman B, Wieschaus E. The segment polarity gene armadillo interacts with the wingless signaling pathway in both embryonic and adult pattern formation. Development. 1991;111(4):1029-1043. doi:10.1242/ dev.111.4.1029
50. Aamir K, Khan HU, Sethi G, Hossain MA, Arya A. Wnt signaling mediates TLR pathway and promote unrestrained adipogenesis and metaflammation: therapeutic targets for obesity and type 2 diabetes. Pharmacol Res. 2020;152:104602. doi:10.1016/j. phrs.2019.104602

51. Liu C, Li Y, Semenov M, et al. Control of beta-catenin phosphorylation/degradation by a dual-kinase mechanism. Cell. 2002;108 (6):837-847. doi:10.1016/s0092-8674(02)00685-2

52. Schuijers J, Mokry M, Hatzis P, Cuppen E, Clevers H. Wntinduced transcriptional activation is exclusively mediated by TCF/LEF. EMBO J. 2014;33(2):146-156. doi:10.1002/ embj. 201385358

53. Novellasdemunt L, Antas P, Li VS. Targeting Wnt signaling in colorectal cancer. A review in the theme: cell signaling: proteins, pathways and mechanisms. Am J Physiol Cell Physiol. 2015;309 (8):C511-521. doi:10.1152/ajpcell.00117.2015

54. Mandal S, Arfuso F, Sethi G, Dharmarajan A, Warrier S. Encapsulated human mesenchymal stem cells (eMSCs) as a novel anti-cancer agent targeting breast cancer stem cells: development of 3D primed therapeutic MSCs. Int J Biochem Cell Biol. 2019;110:59-69. doi:10.1016/j.biocel.2019.02.001

55. Song P, Feng L, Li J, et al. $\beta$-catenin represses miR455-3p to stimulate m6A modification of HSF1 mRNA and promote its translation in colorectal cancer. Mol Cancer. 2020;19(1):129. doi:10.1186/s12943-020-01244-Z

56. Yu Z, Jiang X, Qin L, et al. A novel UBE2T inhibitor suppresses Wnt/ $\beta$-catenin signaling hyperactivation and gastric cancer progression by blocking RACK1 ubiquitination. Oncogene. 2021;40 (5):1027-1042. doi:10.1038/s41388-020-01572-w

57. Hwang ST, Yang MH, Kumar AP, Sethi G, Ahn KS. Corilagin represses epithelial to mesenchymal transition process through modulating Wnt/ $\beta$-catenin signaling cascade. Biomolecules. 2020;10(10):1406. doi:10.3390/biom10101406

58. Yun EJ, Kim S, Hsieh JT, Baek ST. Wnt/ß-catenin signaling pathway induces autophagy-mediated temozolomide-resistance in human glioblastoma. Cell Death Dis. 2020;11(9):771. doi:10.1038/s41419-020-02988-8

59. Cho YH, Ro EJ, Yoon JS, et al. 5-FU promotes stemness of colorectal cancer via $\mathrm{p} 53$-mediated WNT/ $\beta$-catenin pathway activation. Nat Commun. 2020;11(1):5321. doi:10.1038/s41467-02019173-2

60. Wu Q, Ma J, Wei J, Meng W, Wang Y, Shi M. IncRNA SNHG11 promotes gastric cancer progression by activating the Wnt $/ \beta$ catenin pathway and oncogenic autophagy. Mol Ther. 2021;29 (3):1258-1278. doi:10.1016/j.ymthe.2020.10.011

61. Du L, Lee JH, Jiang H, et al. $\beta$-Catenin induces transcriptional expression of PD-L1 to promote glioblastoma immune evasion. J Exp Med. 2020;217(11). doi:10.1084/jem.20191115

62. Deng R, Zuo C, Li Y, et al. The innate immune effector ISG12a promotes cancer immunity by suppressing the canonical Wnt $/ \beta$ catenin signaling pathway. Cell Mol Immunol. 2020;17 (11):1163-1179. doi:10.1038/s41423-020-00549-9

63. Wang $C$, Yan J, Yin $P$, et al. $\beta$-Catenin inhibition shapes tumor immunity and synergizes with immunotherapy in colorectal cancer. Oncoimmunology. 2020;9(1):1809947. doi:10.1080/ 2162402x.2020.1809947

64. Wang Z, Li Z, Wu Q, et al. DNER promotes epithelialmesenchymal transition and prevents chemosensitivity through the Wnt/ $\beta$-catenin pathway in breast cancer. Cell Death Dis. 2020;11(8):642. doi:10.1038/s41419-020-02903-1

65. Bi Z, Li Q, Dinglin X, et al. Nanoparticles (NPs)-meditated LncRNA AFAP1-AS1 silencing to block Wnt/ $\beta$-catenin signaling pathway for synergistic reversal of radioresistance and effective cancer radiotherapy. Adv Sci (Weinh). 2020;7(18):2000915. doi:10.1002/advs.202000915 
66. Kondo Y, Kanai Y, Sakamoto M, et al. Beta-catenin accumulation and mutation of exon 3 of the beta-catenin gene in hepatocellular carcinoma. Jpn J Cancer Res. 1999;90(12):1301-1309. doi:10.1111/j.1349-7006.1999.tb00712.x

67. Wang $\mathrm{H}$, Zhang J, Feng W, et al. PIN1 gene overexpression and beta-catenin gene mutation/expression in hepatocellular carcinoma and their significance. J Huazhong Univ Sci Technol Med Sci. 2007;27(1):54-57. doi:10.1007/s11596-007-0116-z

68. Kitao A, Matsui O, Yoneda N, et al. Hepatocellular carcinoma with $\beta$-catenin mutation: imaging and pathologic characteristics. Radiology. 2015;275(3):708-717. doi:10.1148/radiol.14141315

69. Li P, Cao Y, Li Y, Zhou L, Liu X, Geng M. Expression of Wnt-5a and $\beta$-catenin in primary hepatocellular carcinoma. Int J Clin Exp Pathol. 2014;7(6):3190-3195.

70. Okabe $H$, Kinoshita $H$, Imai $K$, et al. Diverse basis of $\beta$-Catenin activation in human hepatocellular carcinoma: implications in biology and prognosis. PLoS One. 2016;11(4):e0152695 doi:10.1371/journal.pone.0152695

71. Wong CM, Fan ST, Ng IO. Beta-Catenin mutation and overexpression in hepatocellular carcinoma: clinicopathologic and prog nostic significance. Cancer. 2001;92(1):136-145. doi:10.1002/ 1097-0142(20010701)92:1<136::aid-cncr1301>3.0.co;2-r

72. Hale $\mathrm{G}$, Liu $\mathrm{X}, \mathrm{Hu} \mathrm{J}$, et al. Correlation of exon $3 \beta$-catenin mutations with glutamine synthetase staining patterns in hepatocellular adenoma and hepatocellular carcinoma. Mod Pathol. 2016;29(11):1370-1380. doi:10.1038/modpathol.2016.122

73. Cui J, Zhou X, Liu Y, Tang Z. Mutation and overexpression of the beta-catenin gene may play an important role in primary hepatocellular carcinoma among Chinese people. J Cancer Res Clin Oncol. 2001;127(9):577-581. doi:10.1007/s004320100259

74. Yuan RH, Jeng YM, Hu RH, et al. Role of p53 and $\beta$-catenin mutations in conjunction with CK19 expression on early tumor recurrence and prognosis of hepatocellular carcinoma. J Gastrointest Surg. 2011;15(2):321-329. doi:10.1007/s11605010-1373-x

75. Elmileik H, Paterson AC, Kew MC. Beta-catenin mutations and expression, 249serine p53 tumor suppressor gene mutation, and hepatitis B virus infection in southern African Blacks with hepatocellular carcinoma. J Surg Oncol. 2005;91(4):258-263. doi:10.1002/jso.20304

76. Javanmard D, Najafi M, Babaei MR, et al. Investigation of CTNNB1 gene mutations and expression in hepatocellular carcinoma and cirrhosis in association with hepatitis B virus infection. Infect Agent Cancer. 2020;15(1):37. doi:10.1186/s13027-020-00297-5

77. Mo Z, Wang Y, Cao Z, Li P, Zhang S. An integrative analysis reveals the underlying association between CTNNB1 mutation and immunotherapy in hepatocellular carcinoma. Front Oncol. 2020;10(853). doi:10.3389/fonc.2020.00853

78. Harding JJ, Nandakumar S, Armenia J, et al. Prospective genotyping of hepatocellular carcinoma: clinical implications of next-generation sequencing for matching patients to targeted and immune therapies. Clin Cancer Res. 2019;25(7):2116-2126. doi:10.1158/1078-0432.Ccr-18-2293

79. Austinat M, Dunsch R, Wittekind C, Tannapfel A, Gebhardt R, Gaunitz F. Correlation between beta-catenin mutations and expression of Wnt-signaling target genes in hepatocellular carcinoma. Mol Cancer. 2008;7:21. doi:10.1186/1476-4598-7-21

80. Cui J, Zhou X, Liu Y, Tang Z, Romeih M. Wnt signaling in hepatocellular carcinoma: analysis of mutation and expression of beta-catenin, T-cell factor-4 and glycogen synthase kinase 3-beta genes. J Gastroenterol Hepatol. 2003;18(3):280-287. doi:10.1046/j.1440-1746.2003.02973.x

81. Sorkin T, Strautnieks S, Foskett $P$, et al. Multiple $\beta$-catenin mutations in hepatocellular lesions arising in Abernethy malformation. Hum Pathol. 2016;53:153-158. doi:10.1016/j.humpath. 2016.02.025
82. Cagatay T, Ozturk M. P53 mutation as a source of aberrant beta-catenin accumulation in cancer cells. Oncogene. 2002;21 (52):7971-7980. doi:10.1038/sj.onc.1205919

83. Wei BR, Edwards JB, Hoover SB, et al. Altered \{beta\}-catenin accumulation in hepatocellular carcinomas of diethylnitrosamine-exposed rhesus macaques. Toxicol Pathol. 2008;36(7):972-980. doi:10.1177/0192623308327120

84. Pulling LC, Klinge DM, Belinsky SA. p16INK4a and beta-catenin alterations in rat liver tumors induced by NNK. Carcinogenesis. 2001;22(3):461-466. doi:10.1093/carcin/22.3.461

85. Warrier S, Patil M, Bhansali S, Varier L, Sethi G. Designing precision medicine panels for drug refractory cancers targeting cancer stemness traits. Biochim Biophys Acta Rev Cancer. 2021;1875(1):188475. doi:10.1016/j.bbcan.2020.188475

86. Ma Z, Wang YY, Xin HW, et al. The expanding roles of long non-coding RNAs in the regulation of cancer stem cells. Int $J$ Biochem Cell Biol. 2019;108:17-20. doi:10.1016/j. biocel.2019.01.003

87. Lapidot T, Sirard C, Vormoor J, et al. A cell initiating human acute myeloid leukaemia after transplantation into SCID mice. Nature. 1994;367(6464):645-648. doi:10.1038/367645a0

88. Nowell PC. The clonal evolution of tumor cell populations. Science. 1976;194(4260):23-28. doi:10.1126/science.959840

89. Baylin SB, Jones PA. A decade of exploring the cancer epigenome - biological and translational implications. Nat Rev Cancer. 2011;11(10):726-734. doi:10.1038/nrc3130

90. Wang C, Kar S, Lai X, et al. Triple negative breast cancer in Asia: an insider's view. Cancer Treat Rev. 2018;62:29-38. doi:10.1016/ j.ctrv.2017.10.014

91. Bhuvanalakshmi G, Rangappa KS, Dharmarajan A, et al. Breast cancer stem-like cells are inhibited by diosgenin, a steroidal saponin, by the attenuation of the Wnt $\beta$-catenin signaling via the Wnt antagonist secreted frizzled related protein-4. Front Pharmacol. 2017;8:124. doi:10.3389/fphar.2017.00124

92. Schulte LA, López-Gil JC, Sainz BJ, Hermann PC. The cancer stem cell in hepatocellular carcinoma. Cancers (Basel). 2020;12 (3):684. doi:10.3390/cancers 12030684

93. Fan Z, Duan J, Wang L, et al. PTK2 promotes cancer stem cell traits in hepatocellular carcinoma by activating Wnt/ $\beta$-catenin signaling. Cancer Lett. 2019;450:132-143. doi:10.1016/j. canlet.2019.02.040

94. Zhong X, Chen B, Yang Z. The role of tumor-associated macrophages in colorectal carcinoma progression. Cell Physiol Biochem. 2018;45(1):356-365. doi:10.1159/000486816

95. Wang R, Lu M, Chen H, et al. Increased IL-10 mRNA expression in tumor-associated macrophage correlated with late stage of lung cancer. J Exp Clin Cancer Res. 2011;30(1):1-9. doi:10.1186/ 1756-9966-30-62

96. Peng LS, Zhang JY, Teng YS, et al. Tumor-associated monocytes/ macrophages impair NK-cell function via TGF $\beta 1$ in human gastric cancer. Cancer Immunol Res. 2017;5(3):248-256. doi:10.1158/2326-6066.Cir-16-0152

97. Chen Y, Wen H, Zhou C, et al. TNF- $\alpha$ derived from M2 tumorassociated macrophages promotes epithelial-mesenchymal transition and cancer stemness through the $\mathrm{Wnt} / \beta$-catenin pathway in SMMC-7721 hepatocellular carcinoma cells. Exp Cell Res. 2019;378(1):41-50. doi:10.1016/j.yexcr.2019.03.005

98. Cheung PF, Cheung TT, Yip CW, et al. Hepatic cancer stem cell marker granulin-epithelin precursor and $\beta$-catenin expression associate with recurrence in hepatocellular carcinoma. Oncotarget. 2016;7 (16):21644-21657. doi:10.18632/oncotarget.7803

99. Wang JR, Li TZ, Wang C, et al. Liquiritin inhibits proliferation and induces apoptosis in HepG2 hepatocellular carcinoma cells via the ROS-mediated MAPK/AKT/NF- $\kappa \mathrm{B}$ signaling pathway. Naunyn Schmiedebergs Arch Pharmacol. 2020;393 (10):1987-1999. doi:10.1007/s00210-019-01763-7 
100. Kirtonia A, Sethi G, Garg M. The multifaceted role of reactive oxygen species in tumorigenesis. Cell Mol Life Sci. 2020;77 (22):4459-4483. doi:10.1007/s00018-020-03536-5

101. Li B, Cao Y, Meng G, et al. Targeting glutaminase 1 attenuates stemness properties in hepatocellular carcinoma by increasing reactive oxygen species and suppressing Wnt/beta-catenin pathway. EBioMedicine. 2019;39:239-254. doi:10.1016/j.ebiom.2018.11.063

102. Ashrafizadeh M, Ahmadi Z, Farkhondeh T, Samarghandian S. Resveratrol targeting the Wnt signaling pathway: A focus on therapeutic activities. J Cell Physiol. 2020;235(5):4135-4145. doi:10.1002/jcp. 29327

103. Zheng W, Yao M, Wu M, Yang J, Yao D, Wang L. Secretory clusterin promotes hepatocellular carcinoma progression by facilitating cancer stem cell properties via AKT/GSK-3 $\beta / \beta$-catenin axis. $J$ Transl Med. 2020;18(1):81. doi:10.1186/s12967-020-02262-7

104. Liu M, Bamodu OA, Kuo KT, et al. Downregulation of cancer stemness by novel diterpenoid ovatodiolide inhibits hepatic cancer stem cell-like traits by repressing Wnt/[Formula: see text]-catenin signaling. Am J Chin Med. 2018;46(4):891-910. doi:10.1142/s0192415x18500477

105. Zheng X, Li C, Yu K, et al. Aquaporin-9, mediated by IGF2, suppresses liver cancer stem cell properties via augmenting ROS/ $\beta$-catenin/FOXO3a signaling. Mol Cancer Res. 2020;18 (7):992-1003. doi:10.1158/1541-7786.Mcr-19-1180

106. Zhu K, Li J, Li J, et al. Ring1 promotes the transformation of hepatic progenitor cells into cancer stem cells through the Wnt/ $\beta$ catenin signaling pathway. J Cell Biochem. 2019. doi:10.1002/ jcb.29496

107. Raghunath A, Sundarraj K, Arfuso F, Sethi G, Perumal E. Dysregulation of Nrf2 in hepatocellular carcinoma: role in cancer progression and chemoresistance. Cancers (Basel). 2018;10 (12):481. doi:10.3390/cancers10120481

108. Lee H, Baek SH, Lee JH, et al. Isorhynchophylline, a potent plant alkaloid, induces apoptotic and anti-metastatic effects in human hepatocellular carcinoma cells through the modulation of diverse cell signaling cascades. Int $J$ Mol Sci. 2017;18(5):1095. doi:10.3390/ijms 18051095

109. Torbenson MS. Hepatocellular carcinoma: making sense of morphological heterogeneity, growth patterns, and subtypes. Hum Pathol. 2021;112:86-101. doi:10.1016/j.humpath.2020.12.009

110. Wang $\mathrm{T}$, Jin $\mathrm{H}, \mathrm{Hu} \mathrm{J}$, et al. COL4A1 promotes the growth and metastasis of hepatocellular carcinoma cells by activating FAK-Src signaling. J Exp Clin Cancer Res. 2020;39(1):148. doi:10.1186/s13046-020-01650-7

111. Myojin Y, Hikita H, Sugiyama M, et al. Hepatic stellate cells in hepatocellular carcinoma promote tumor growth via growth differentiation factor 15 production. Gastroenterology. 2021;160 (5):1741-1754.e1716. doi:10.1053/j.gastro.2020.12.015

112. Wang J, Wei W, Tang Q, et al. Oxysophocarpine suppresses hepatocellular carcinoma growth and sensitizes the therapeutic blockade of anti-Lag-3 via reducing FGL1 expression. Cancer Med. 2020;9(19):7125-7136. doi:10.1002/cam4.3151

113. Jiang J, Xu B, Zheng Y, Guo X, Chen F. Spindle and kinetochoreassociated protein 2 facilitates the proliferation and invasion of hepatocellular carcinoma via the regulation of $\mathrm{Wnt} / \beta$-catenin signaling. Exp Cell Res. 2020;395(1):112181. doi:10.1016/j. yexcr.2020.112181

114. Fan W, Du F, Liu X. Phosphatidylinositol 4-phosphate adaptor protein 2 accelerates the proliferation and invasion of hepatocellular carcinoma cells by enhancing Wnt/ $\beta$-catenin signaling. $J$ Bioenerg Biomembr. 2020;52(5):301-309. doi:10.1007/ s10863-020-09852-6

115. Zhu M, Gong Z, Wu Q, et al. Homoharringtonine suppresses tumor proliferation and migration by regulating EphB4-mediated $\beta$-catenin loss in hepatocellular carcinoma. Cell Death Dis. 2020;11(8):632. doi:10.1038/s41419-020-02902-2
116. Siqueira EDS, Concato VM, Tomiotto-Pellissier F, et al. Transchalcone induces death by autophagy mediated by p53 upregulation and $\beta$-catenin down-regulation on human hepatocellular carcinoma HuH7.5 cell line. Phytomedicine. 2021;80:153373. doi:10.1016/j.phymed.2020.153373

117. Tang N, Cai X, Peng L, Liu H, Chen Y. TCP1 regulates Wnt7b/ßcatenin pathway through P53 to influence the proliferation and migration of hepatocellular carcinoma cells. Signal Transduct Target Ther. 2020;5(1):169. doi:10.1038/s41392-020-00278-5

118. Wood SA, Pascoe WS, Ru K, Hirchenhain J, Kemler R, Mattick JS. Cloning and expression analysis of a novel mouse gene with sequence similarity to the Drosophila fat facets gene. Mech Dev. 1997;63(1):29-38. doi:10.1016/s0925-4773(97)00672-2

119. Pérez-Mancera PA, Rust AG, van der Weyden L, et al. The deubiquitinase USP9X suppresses pancreatic ductal adenocarcinoma. Nature. 2012;486(7402):266-270. doi:10.1038/ nature 11114

120. Jie X, Fong WP, Zhou R, et al. USP9X-mediated KDM4C deubiquitination promotes lung cancer radioresistance by epigenetically inducing TGF- $\beta 2$ transcription. Cell Death Differ. 2021;28 (7):2095-2111. doi:10.1038/s41418-021-00740-z

121. Sulkshane P, Pawar SN, Waghole R, et al. Elevated USP9X drives early-to-late-stage oral tumorigenesis via stabilisation of anti-apoptotic MCL-1 protein and impacts outcome in oral cancers. $B r \quad J$ Cancer. 2021;125(4):547-560. doi:10.1038/ s41416-021-01421-x

122. Wrobel L, Siddiqi FH, Hill SM, et al. mTORC2 assembly is regulated by USP9X-mediated deubiquitination of RICTOR. Cell Rep. 2020;33(13):108564. doi:10.1016/j.celrep.2020.108564

123. Lu WX, Gan GS, Yang B. Knockdown of USP9X reverses cisplatin resistance by decreasing $\beta$-catenin expression in nasopharyngeal carcinoma cells. Neoplasma. 2021;68(4):810-822. doi:10.4149/neo_2021_201227N1410

124. Chen MY, Li ZP, Sun ZN, Ma M. USP9X promotes the progression of hepatocellular carcinoma by regulating beta-catenin. Ir J Med Sci. 2020;189(3):865-871. doi:10.1007/s11845-020-02199-2

125. Zhang Y, Li H, Wang J, Geng X, Hai J. Meningioma-associated protein 30 accelerates the proliferation and invasion of hepatocellular carcinoma by modulating Wnt/GSK-3 $\beta / \beta$-catenin signaling. $J$ Bioenerg Biomembr. 2021;53(1):73-83. doi:10.1007/s10863020-09864-2

126. Fang L, Gao C, Bai RX, Wang HF, Du SY. Overexpressed sFRP3 exerts an inhibitory effect on hepatocellular carcinoma via inactivation of the $\mathrm{Wnt} / \beta$-catenin signaling pathway. Cancer Gene Ther. 2020. doi:10.1038/s41417-020-0201-Z

127. Yin Z, Xu W, Xu H, Zheng J, Gu Y. Overexpression of HDAC6 suppresses tumor cell proliferation and metastasis by inhibition of the canonical Wnt/B-catenin signaling pathway in hepatocellular carcinoma. Oncol Lett. 2018;16(6):7082-7090. doi:10.3892/ol.2018.9504

128. Patra S, Mishra SR, Behera BP, et al. Autophagy-modulating phytochemicals in cancer therapeutics: current evidences and future perspectives. Semin Cancer Biol. 2020:S1044-1579X (1020)30104-30108. doi:10.1016/j.semcancer.2020.05.008

129. Ashrafizadeh M, Ahmadi Z, Farkhondeh T, Samarghandian S. Autophagy regulation using luteolin: new insight into its anti-tumor activity. Cancer Cell Int. 2020;20(1):537. doi:10.1186/s12935-020-01634-9

130. Ashrafizadeh M, Ahmadi Z, Farkhondeh T, Samarghandian S. Autophagy as a molecular target of quercetin underlying its protective effects in human diseases. Arch Physiol Biochem. 2019;1-9. doi:10.1080/13813455.2019.1671458

131. Fan Q, Yang L, Zhang X, et al. Autophagy promotes metastasis and glycolysis by upregulating MCT1 expression and Wnt/ $\beta$ catenin signaling pathway activation in hepatocellular carcinoma cells. J Exp Clin Cancer Res. 2018;37(1):9. doi:10.1186/s13046018-0673-y 
132. Turcios L, Chacon E, Garcia C, et al. Autophagic flux modulation by Wnt/ $\beta$-catenin pathway inhibition in hepatocellular carcinoma. PLoS One. 2019;14(2):e0212538. doi:10.1371/journal. pone. 0212538

133. Lv E, Yu C, Rao D, Huang W. LncRNA influence sequential steps of hepatocellular carcinoma metastasis. Biomed Pharmacother. 2021;136:111224. doi:10.1016/j.biopha.2021.111224

134. Siveen KS, Ahn KS, Ong TH, et al. Y-tocotrienol inhibits angiogenesis-dependent growth of human hepatocellular carcinoma through abrogation of AKT/mTOR pathway in an orthotopic mouse model. Oncotarget. 2014;5(7):1897-1911. doi:10.18632/oncotarget.1876

135. Zuo Q, He J, Zhang S, et al. PPAR $\gamma$ coactivator- $1 \alpha$ suppresses metastasis of hepatocellular carcinoma by inhibiting Warburg effect by PPAR $\gamma$-dependent WNT/ $\beta$-catenin/pyruvate dehydrogenase kinase isozyme 1 axis. Hepatology. 2021;73(2):644-660. doi: $10.1002 /$ hep. 31280

136. Chen S, He Z, Zhu C, et al. TRIM37 mediates chemoresistance and maintenance of stemness in pancreatic cancer cells via ubiquitination of PTEN and activation of the AKT-GSK-3 $\beta-\beta$ catenin signaling pathway. Front Oncol. 2020;10:554787. doi: $10.3389 /$ fonc. 2020.554787

137. Song M, Pan Q, Yang J, et al. Galectin-3 favours tumour metastasis via the activation of $\beta$-catenin signalling in hepatocellular carcinoma. Br J Cancer. 2020;123(10):1521-1534. doi:10.1038/ s41416-020-1022-4

138. Lee JH, Chinnathambi A, Alharbi SA, Shair OHM, Sethi G, Ahn KS. Farnesol abrogates epithelial to mesenchymal transition process through regulating Akt/mTOR pathway. Pharmacol Res. 2019;150:104504. doi:10.1016/j.phrs.2019.104504

139. Ashrafizadeh M, Zarrabi A, Hushmandi K, et al. Association of the epithelial-mesenchymal transition (EMT) with cisplatin resistance. Int J Mol Sci. 2020;21(11):4002. doi:10.3390/ijms21114002

140. Ashrafizadeh M, Ang HL, Moghadam ER, et al. MicroRNAs and their influence on the ZEB family: Mechanistic aspects and therapeutic applications in cancer therapy. Biomolecules. 2020;10 (7):1040. doi:10.3390/biom10071040

141. Tian W, Li J, Wang Z, et al. HYD-PEP06 suppresses hepatocellular carcinoma metastasis, epithelial-mesenchymal transition and cancer stem cell-like properties by inhibiting PI3K/AKT and WNT/B-catenin signaling activation. Acta Pharm Sin B. 2021;11 (6):1592-1606. doi:10.1016/j.apsb.2021.03.040

142. Chen K, Li Z, Zhang M, et al. miR-876 inhibits EMT and liver fibrosis via POSTN to suppress metastasis in hepatocellular carcinoma. Biomed Res Int. 2020;2020:1964219. doi:10.1155/ 2020/1964219

143. Lu J, Zhao Z, Ma Y. miR-186 represses proliferation, migration, invasion, and EMT of hepatocellular carcinoma via directly targeting CDK6. Oncol Res. 2020;28(5):509-518. doi:10.3727/ 096504020x15954139263808

144. Hong X, Luo H, Zhu G, et al. SSR2 overexpression associates with tumorigenesis and metastasis of Hepatocellular Carcinoma through modulating EMT. J Cancer. 2020;11(19):5578-5587. doi: $10.7150 /$ jca. 44788

145. Guo F, Wang H, Jiang M, et al. TDP-43 induces EMT and promotes hepatocellular carcinoma metastasis via activating Wnt/B-catenin signaling pathway. Am J Cancer Res. 2020;10 (10):3285-3301

146. Han Q, Chen CA, Yang W, et al. ATP-citrate lyase regulates stemness and metastasis in hepatocellular carcinoma via the Wnt/B-catenin signaling pathway. Hepatobiliary Pancreat Dis Int. 2021;20(3):251-261. doi:10.1016/j.hbpd.2020.05.010

147. Ren Y, Wang Y, Hao S, et al. NFE2L3 promotes malignant behavior and EMT of human hepatocellular carcinoma (HepG2) cells via Wnt/ $\beta$-catenin pathway. $J$ Cancer. 2020;11 (23):6939-6949. doi:10.7150/jca.48100
148. Du J, Zhu Z, Xu L, et al. ARHGEF11 promotes proliferation and epithelial-mesenchymal transition of hepatocellular carcinoma through activation of $\beta$-catenin pathway. Aging (Albany NY). 2020;12(20):20235-20253. doi:10.18632/aging.103772

149. Lee S, Choi EJ, Cho EJ, et al. Inhibition of PI3K/Akt signaling suppresses epithelial-to-mesenchymal transition in hepatocellular carcinoma through the Snail/GSK-3/beta-catenin pathway. Clin Mol Hepatol. 2020;26(4):529-539. doi:10.3350/cmh.2019.0056n

150. Page-McCaw A, Ewald AJ, Werb Z. Matrix metalloproteinases and the regulation of tissue remodelling. Nat Rev Mol Cell Biol. 2007;8(3):221-233. doi:10.1038/nrm2125

151. Cook R, Sarker H, Fernandez-Patron C. Pathologies of matrix metalloproteinase-2 underactivity: a perspective on a neglected condition (1). Can J Physiol Pharmacol. 2019;97(6):486-492. doi:10.1139/cjpp-2018-0525

152. Lu Z, Chang L, Zhou H, et al. Arctigenin attenuates tumor metastasis through inhibiting epithelial-mesenchymal transition in hepatocellular carcinoma via suppressing GSK3 $\beta$-dependent $\mathrm{Wnt} / \beta$-catenin signaling pathway in vivo and in vitro. Front Pharmacol. 2019;10:937. doi:10.3389/fphar.2019.00937

153. Gai JQ, Sheng X, Qin JM, Sun K, Zhao W, Ni L. The effect and mechanism of bufalin on regulating hepatocellular carcinoma cell invasion and metastasis via Wnt/ $\beta$-catenin signaling pathway. Int J Oncol. 2016;48(1):338-348. doi:10.3892/ijo.2015.3250

154. Liu FH, Cui YP, He YK, Shu RH. FBXO17 promotes malignant progression of hepatocellular carcinoma by activating wnt $/ \beta$ catenin pathway. Eur Rev Med Pharmacol Sci. 2019;23 (19):8265-8273. doi:10.26355/eurrev_201910_19137

155. Kwee SA, Tiirikainen M. Beta-catenin activation and immunotherapy resistance in hepatocellular carcinoma: mechanisms and biomarkers. Hepatoma Res. 2021;7. doi:10.20517/23945079.2020.124

156. Matsuda A, Ishiguro K, Yan IK, Patel T. Extracellular vesiclebased therapeutic targeting of $\beta$-catenin to modulate anticancer immune responses in hepatocellular cancer. Hepatol Commun. 2019;3(4):525-541. doi:10.1002/hep4.1311

157. Ruiz de Galarreta M, Bresnahan E, Molina-Sánchez P, et al. $\beta$ Catenin activation promotes immune escape and resistance to Anti-PD-1 therapy in hepatocellular carcinoma. Cancer Discov. 2019;9(8):1124-1141. doi:10.1158/2159-8290.Cd-19-0074

158. Liu R, Li Y, Tian L, et al. Gankyrin drives metabolic reprogramming to promote tumorigenesis, metastasis and drug resistance through activating $\beta$-catenin/c-Myc signaling in human hepatocellular carcinoma. Cancer Lett. 2019;443:34-46. doi:10.1016/j. canlet.2018.11.030

159. Toh TB, Lim JJ, Hooi L, Rashid M, Chow EK. Targeting Jak/Stat pathway as a therapeutic strategy against SP/CD44+ tumorigenic cells in Akt/ß-catenin-driven hepatocellular carcinoma. J Hepatol. 2020;72(1):104-118. doi:10.1016/j.jhep.2019.08.035

160. Deng L, Sun J, Chen X, Liu L, Wu D. Nek2 augments sorafenib resistance by regulating the ubiquitination and localization of $\beta$ catenin in hepatocellular carcinoma. $J$ Exp Clin Cancer Res. 2019;38(1):316. doi:10.1186/s13046-019-1311-z

161. Huynh H, Ong R, Goh KY, et al. Sorafenib/MEK inhibitor combination inhibits tumor growth and the Wnt/ $\beta$-catenin pathway in xenograft models of hepatocellular carcinoma. Int $J$ Oncol. 2019;54(3):1123-1133. doi:10.3892/ijo.2019.4693

162. Wu CX, Wang XQ, Chok SH, et al. Blocking CDK1/PDK1/ $\beta$ Catenin signaling by CDK1 inhibitor RO3306 increased the efficacy of sorafenib treatment by targeting cancer stem cells in a preclinical model of hepatocellular carcinoma. Theranostics. 2018;8(14):3737-3750. doi:10.7150/thno.25487

163. Burke Z, Oliver G. Prox 1 is an early specific marker for the developing liver and pancreas in the mammalian foregut endoderm. Mech Dev. 2002;118(1-2):147-155. doi:10.1016/ s0925-4773(02)00240-x 
164. Liu Y, Zhang JB, Qin Y, et al. PROX1 promotes hepatocellular carcinoma metastasis by way of up-regulating hypoxia-inducible factor $1 \alpha$ expression and protein stability. Hepatology. 2013;58 (2):692-705. doi:10.1002/hep.26398

165. Liu Y, Ye X, Zhang JB, et al. PROX1 promotes hepatocellular carcinoma proliferation and sorafenib resistance by enhancing $\beta$ catenin expression and nuclear translocation. Oncogene. 2015;34 (44):5524-5535. doi:10.1038/onc.2015.7

166. Zhou Y, Liang C, Xue F, et al. Salinomycin decreases doxorubicin resistance in hepatocellular carcinoma cells by inhibiting the $\beta$-catenin /TCF complex association via FOXO3a activation. Oncotarget. 2015;6(12):10350-10365. doi:10.18632/oncotarget.3585

167. Zhang J, Zhang X, Li J, Song Z. Systematic analysis of the ABC transporter family in hepatocellular carcinoma reveals the importance of ABCB6 in regulating ferroptosis. Life Sci. 2020;257:118131. doi:10.1016/j.lfs.2020.118131

168. Chen Z, Pan T, Jiang D, et al. The lncRNA-GAS5/miR-221-3p/ DKK2 Axis modulates ABCB1-mediated adriamycin resistance of breast cancer via the Wnt/ $\beta$-catenin signaling pathway. Mol Ther Nucleic Acids. 2020;19:1434-1448. doi:10.1016/j. omtn.2020.01.030

169. Chen Z, Huang C, Ma T, et al. Reversal effect of quercetin on multidrug resistance via FZD7/ $\beta$-catenin pathway in hepatocellular carcinoma cells. Phytomedicine. 2018;43:37-45. doi:10.1016/ j.phymed.2018.03.040

170. Negri FV, Dal Bello B, Porta C, et al. Expression of pERK and VEGFR-2 in advanced hepatocellular carcinoma and resistance to sorafenib treatment. Liver Int. 2015;35(8):2001-2008. doi:10.1111/liv.12778

171. Zheng W, Sai W, Yao M, et al. Silencing clusterin gene transcription on effects of multidrug resistance reversing of human hepatoma HepG2/ADM cells. Tumour Biol. 2015;36(5):3995-4003. doi:10.1007/s13277-015-3043-9

172. Mirzaei S, Zarrabi A, Hashemi F, et al. Regulation of Nuclear Factor-KappaB (NF- $\kappa \mathrm{B})$ signaling pathway by non-coding RNAs in cancer: inhibiting or promoting carcinogenesis? Cancer Lett. 2021;509:63-80. doi:10.1016/j.canlet.2021.03.025

173. Ashrafizadeh M, Hushmandi K, Hashemi M, et al. Role of microRNA/epithelial-to-mesenchymal transition axis in the metastasis of bladder cancer. Biomolecules. 2020;10(8):1159. doi:10.3390/biom10081159

174. Ashrafizadeh M, Zarrabi A, Hushmandi K, et al. Lung cancer cells and their sensitivity/resistance to cisplatin chemotherapy: role of microRNAs and upstream mediators. Cell Signal. 2021;78:109871. doi:10.1016/j.cellsig.2020.109871

175. Karimkhanloo H, Mohammadi-Yeganeh S, Hadavi R, Koochaki A, Paryan M. Potential role of miR-214 in $\beta$-catenin gene expression within hepatocellular carcinoma. Mol Biol Rep. 2020;47(10):7429-7437. doi:10.1007/s11033-020-05798-5

176. Xin RQ, Li WB, Hu ZW, Wu ZX, Sun W. MiR-329-3p inhibits hepatocellular carcinoma cell proliferation and migration through USP22-Wnt/ $\beta$-Catenin pathway. Eur Rev Med Pharmacol Sci. 2020;24(19):9932-9939. doi:10.26355/eurrev_202010_23204

177. Ai N, Li B, Li L, et al. MicroRNA-466 inhibits cancer cell migration and invasion in hepatocellular carcinoma by indirectly mediating the downregulation of ROCK2. Exp Ther Med. 2019;18(2):1493-1499. doi:10.3892/etm.2019.7709

178. Jia C, Tang D, Sun C, et al. MicroRNA-466 inhibits the aggressive behaviors of hepatocellular carcinoma by directly targeting metadherin. Oncol Rep. 2018;40(6):3890-3898. doi:10.3892/ or.2018.6763

179. Li J, Yan S. MiR-466 inhibits the progression of severe hepatocellular carcinoma via regulating FMNL2-mediated activation of NF$\kappa \mathrm{B}$ and Wnt/B-catenin pathways. J Oncol. 2021;2021:3554219. doi: $10.1155 / 2021 / 3554219$
180. Cui X, Jiang X, Wei C, Xing Y, Tong G. Astragaloside IV suppresses development of hepatocellular carcinoma by regulating miR-150-5p/ $/$-catenin axis. Environ Toxicol Pharmacol. 2020;78:103397. doi:10.1016/j.etap.2020.103397

181. Wang Y, Sun B, Sun H, et al. Regulation of proliferation, angiogenesis and apoptosis in hepatocellular carcinoma by miR-26b5p. Tumour Biol. 2016;37(8):10965-10979. doi:10.1007/s13277016-4964-7

182. Li H, Sun Q, Han B, Yu X, Hu B, Hu S. MiR-26b inhibits hepatocellular carcinoma cell proliferation, migration, and invasion by targeting EphA2. Int $J$ Clin Exp Pathol. 2015;8 (5):4782-4790.

183. Han W, Li N, Liu J, Sun Y, Yang X, Wang Y. MicroRNA-26b-5p enhances $\mathrm{T}$ cell responses by targeting PIM-2 in hepatocellular carcinoma. Cell Signal. 2019;59:182-190. doi:10.1016/j. cellsig.2018.11.011

184. Hu X, Wang R, Ren Z, et al. MiR-26b suppresses hepatocellular carcinoma development by negatively regulating ZNRD1 and Wnt/ß-catenin signaling. Cancer Med. 2019;8(17):7359-7371. doi:10.1002/cam4.2613

185. Lu C, Jia S, Zhao S, Shao X. MiR-342 regulates cell proliferation and apoptosis in hepatocellular carcinoma through Wnt/ $\beta$-catenin signaling pathway. Cancer Biomark. 2019;25(1):115-126. doi:10.3233/cbm-192399

186. Wang H, Ou J, Jian Z, Ou Y. miR-186 modulates hepatocellular carcinoma cell proliferation and mobility via targeting MCRS1mediated Wnt/ $\beta$-catenin signaling. J Cell Physiol. 2019;234 (12):23135-23145. doi:10.1002/jcp.28878

187. Paskeh MDA, Mirzaei S, Gholami MH, et al. Cervical cancer progression is regulated by SOX transcription factors: Revealing signaling networks and therapeutic strategies. Biomed Pharmacother. 2021;144:112335. doi:10.1016/j.biopha.2021.112335

188. Ashrafizadeh M, Zarrabi A, Orouei S, et al. Interplay between SOX9 transcription factor and microRNAs in cancer. Int $\mathrm{J}$ Biol Macromol. 2021;183:681-694. doi:10.1016/j.ijbiomac.2021.04.185

189. Abadi AJ, Zarrabi A, Hashemi F, et al. The role of SOX family transcription factors in gastric cancer. Int $J$ Biol Macromol. 2021;180:608-624. doi:10.1016/j.ijbiomac.2021.02.202

190. Ashrafizadeh M, Taeb S, Hushmandi K, et al. Cancer and SOX proteins: new insight into their role in ovarian cancer progression/ inhibition. Pharmacol Res. 2020;161:105159. doi:10.1016/j. phrs.2020.105159

191. Cao X, Zhang J, Apaer S, Yao G, Li T. microRNA-19a-3p and microRNA-376c-3p promote hepatocellular carcinoma progression through SOX6-mediated Wnt/ $\beta$-catenin signaling pathway. Int J Gen Med. 2021;14:89-102. doi:10.2147/ijgm.S278538

192. Lin X, Zuo S, Luo R, et al. HBX-induced miR-5188 impairs FOXO1 to stimulate $\beta$-catenin nuclear translocation and promotes tumor stemness in hepatocellular carcinoma. Theranostics. 2019;9(25):7583-7598. doi:10.7150/thno.37717

193. Tao X, Yang X, Wu K, et al. miR-629-5p promotes growth and metastasis of hepatocellular carcinoma by activating $\beta$-catenin. Exp Cell Res. 2019;380(2):124-130. doi:10.1016/j.yexcr.2019.03.042

194. Hu Z, Wang P, Lin J, et al. MicroRNA-197 promotes metastasis of hepatocellular carcinoma by activating Wnt/ $\beta$-catenin signaling. Cell Physiol Biochem. 2018;51(1):470-486. doi:10.1159/ 000495242

195. Tuo H, Wang Y, Wang L, et al. MiR-324-3p promotes tumor growth through targeting DACT1 and activation of Wnt/ $\beta$ catenin pathway in hepatocellular carcinoma. Oncotarget. 2017;8(39):65687-65698. doi:10.18632/oncotarget.20058

196. Yang N, Zhou J, Li Q, Han F, Yu Z. miR-96 exerts carcinogenic effect by activating AKT/GSK-3 $\beta / \beta$-catenin signaling pathway through targeting inhibition of FOXO1 in hepatocellular carcinoma. Cancer Cell Int. 2019;19:38. doi:10.1186/s12935-0190756-7 
197. Zhuang L, Wang X, Wang Z, et al. MicroRNA-23b functions as an oncogene and activates AKT/GSK $3 \beta / \beta$-catenin signaling by targeting ST7L in hepatocellular carcinoma. Cell Death Dis. 2017;8(5):e2804. doi:10.1038/cddis.2017.216

198. Guo Y, Chen L, Sun C, Yu C. MicroRNA-500a promotes migration and invasion in hepatocellular carcinoma by activating the Wnt/ $\beta$-catenin signaling pathway. Biomed Pharmacother. 2017;91:13-20. doi:10.1016/j.biopha.2017.04.018

199. Pandya G, Kirtonia A, Sethi G, Pandey AK, Garg M. The implication of long non-coding RNAs in the diagnosis, pathogenesis and drug resistance of pancreatic ductal adenocarcinoma and their possible therapeutic potential. Biochim Biophys Acta Rev Cancer. 2020;1874(2):188423. doi:10.1016/j.bbcan.2020.188423

200. Ashrafizadeh M, Gholami MH, Mirzaei S, et al. Dual relationship between long non-coding RNAs and STAT3 signaling in different cancers: New insight to proliferation and metastasis. Life Sci. 2021;270:119006. doi:10.1016/j.1fs.2020.119006

201. Mattick JS, Amaral PP, Dinger ME, Mercer TR, Mehler MF. RNA regulation of epigenetic processes. Bioessays. 2009;31 (1):51-59. doi:10.1002/bies.080099

202. Mishra S, Verma SS, Rai V, et al. Long non-coding RNAs are emerging targets of phytochemicals for cancer and other chronic diseases. Cell Mol Life Sci. 2019;76(10):1947-1966. doi:10.1007/ s00018-019-03053-0

203. Ørom UA, Derrien T, Beringer M, et al. Long noncoding RNAs with enhancer-like function in human cells. Cell. 2010;143 (1):46-58. doi:10.1016/j.cell.2010.09.001

204. Thakur KK, Kumar A, Banik K, et al. Long noncoding RNAs in triple-negative breast cancer: a new frontier in the regulation of tumorigenesis. J Cell Physiol. 2021. doi:10.1002/jcp.30463

205. Ashrafizaveh S, Ashrafizadeh M, Zarrabi A, et al. Long non-coding RNAs in the doxorubicin resistance of cancer cells. Cancer Lett. 2021;508:104-114. doi:10.1016/j.canlet.2021.03.018

206. Sheng JQ, Wang MR, Fang D, et al. LncRNA NBR2 inhibits tumorigenesis by regulating autophagy in hepatocellular carcinoma. Biomed Pharmacother. 2021;133:111023. doi:10.1016/j.biopha.2020.111023

207. Zhang H, Xu HB, Kurban E, Luo HW. LncRNA SNHG14 promotes hepatocellular carcinoma progression via H3K27 acetylation activated PABPC1 by PTEN signaling. Cell Death Dis. 2020;11(8):646. doi:10.1038/s41419-020-02808-Z

208. Zhao JT, Chi BJ, Sun Y, et al. LINC00174 is an oncogenic IncRNA of hepatocellular carcinoma and regulates miR-320/ S100A10 axis. Cell Biochem Funct. 2020;38(7):859-869. doi:10.1002/cbf.3498

209. Yang Y, Ye YC, Chen Y, et al. Crosstalk between hepatic tumor cells and macrophages via $\mathrm{Wnt} / \beta$-catenin signaling promotes M2-like macrophage polarization and reinforces tumor malignant behaviors. Cell Death Dis. 2018;9(8):793. doi:10.1038/s41419-018-0818-0

210. Ye YC, Zhao JL, Lu YT, et al. NOTCH signaling via WNT regulates the proliferation of alternative, CCR2-independent tumor-associated macrophages in hepatocellular carcinoma. Cancer Res. 2019;79 (16):4160-4172. doi:10.1158/0008-5472.CAN-18-1691

211. Tian X, Wu Y, Yang Y, et al. Long noncoding RNA LINC00662 promotes M2 macrophage polarization and hepatocellular carcinoma progression via activating Wnt/ $\beta$-catenin signaling. $\mathrm{Mol}$ Oncol. 2020;14(2):462-483. doi:10.1002/1878-0261.12606

212. Fu X, Zhu X, Qin F, et al. Linc00210 drives Wnt/ $\beta$-catenin signaling activation and liver tumor progression through CTNNBIP1-dependent manner. Mol Cancer. 2018;17(1):73. doi:10.1186/s12943-018-0783-3

213. Ma YK, Shen TH, Yang XY. Upregulation of LncRNA FAM83HAS1 in hepatocellular carcinoma promotes cell proliferation, migration and invasion by Wnt/ $\beta$-catenin pathway. Eur Rev Med Pharmacol Sci. 2019;23(18):7855-7862. doi:10.26355/ eurrev_201909_18995
214. Chen W, You J, Zheng Q, Zhu YY. Downregulation of IncRNA OGFRP1 inhibits hepatocellular carcinoma progression by AKT/ mTOR and Wnt/ $\beta$-catenin signaling pathways. Cancer Manag Res. 2018;10:1817-1826. doi:10.2147/cmar.S164911

215. Yao X, You G, Zhou C, Zhang D. LncRNA ASB16-AS1 promotes growth and invasion of hepatocellular carcinoma through regulating $\mathrm{miR}-1827 /$ FZD4 axis and activating $\mathrm{Wnt} / \beta$-catenin pathway. Cancer Manag Res. 2019;11:9371-9378. doi:10.2147/ cmar.S220434

216. Lin Y, Jian Z, Jin H, et al. Long non-coding RNA DLGAP1-AS1 facilitates tumorigenesis and epithelial-mesenchymal transition in hepatocellular carcinoma via the feedback loop of miR-26a/b-5p/ IL-6/JAK2/STAT3 and Wnt/ $\beta$-catenin pathway. Cell Death Dis. 2020;11(1):34. doi:10.1038/s41419-019-2188-7

217. Chen B, Lan J, Xiao Y, et al. Long noncoding RNA TP53TG1 suppresses the growth and metastasis of hepatocellular carcinoma by regulating the $\mathrm{PRDX} 4 / \beta$-catenin pathway. Cancer Lett. 2021;513:75-89. doi:10.1016/j.canlet.2021.04.022

218. Liang WC, Ren JL, Wong CW, et al. LncRNA-NEF antagonized epithelial to mesenchymal transition and cancer metastasis via cisregulating FOXA2 and inactivating $\mathrm{Wnt} / \beta$-catenin signaling. Oncogene. 2018;37(11):1445-1456. doi:10.1038/s41388-017-0041-y

219. Song XZ, Xu XJ, Ren XN, Ruan XX, Wang YL, Yao TT. LncRNA ANCR suppresses the progression of hepatocellular carcinoma through the inhibition of $\mathrm{Wnt} / \beta$-catenin signaling pathway. Onco Targets Ther. 2020;13:8907-8917. doi:10.2147/ott. S260556

220. Li QY, Yang K, Liu FG, et al. Long noncoding RNA CASC2c inhibited cell proliferation in hepatocellular carcinoma by inactivated ERK1/2 and Wnt/ $\beta$-catenin signaling pathway. Clin Transl Oncol. 2020;22(3):302-310. doi:10.1007/s12094-019-02223-7

221. Sanger HL, Klotz G, Riesner D, Gross HJ, Kleinschmidt AK. Viroids are single-stranded covalently closed circular RNA molecules existing as highly base-paired rod-like structures. Proc Natl Acad Sci U S A. 1976;73(11):3852-3856. doi:10.1073/pnas.73.11.3852

222. Jiang $\mathrm{S}, \mathrm{Fu} \mathrm{R}$, Shi J, et al. CircRNA-mediated regulation of angiogenesis: A new chapter in cancer biology. Front Oncol. 2021;11:553706. doi:10.3389/fonc.2021.553706

223. Xiao W, Li J, Hu J, et al. Circular RNAs in cell cycle regulation: mechanisms to clinical significance. Cell Prolif. 2021:e13143. doi:10.1111/cpr.13143

224. Chen S, Yang X, Yu C, et al. The potential of circRNA as a novel diagnostic biomarker in cervical cancer. $J$ Oncol. 2021;2021:5529486. doi:10.1155/2021/5529486

225. Xu J, Ji L, Liang Y, et al. CircRNA-SORE mediates sorafenib resistance in hepatocellular carcinoma by stabilizing YBX1. Signal Transduct Target Ther. 2020;5(1):298. doi:10.1038/ s41392-020-00375-5

226. Huang G, Liang M, Liu H, et al. CircRNA hsa_circRNA 104348 promotes hepatocellular carcinoma progression through modulating miR-187-3p/RTKN2 axis and activating Wnt/ $\beta$-catenin pathway. Cell Death Dis. 2020;11(12):1065. doi:10.1038/s41419-02003276-1

227. Liu X, Yang L, Jiang D, Lu W, Zhang Y. Circ-DENND4C upregulates TCF4 expression to modulate hepatocellular carcinoma cell proliferation and apoptosis via activating Wnt/ $\beta$-catenin signal pathway. Cancer Cell Int. 2020;20:295. doi:10.1186/s12935020-01346-0

228. Tan A, Li Q, Chen L. CircZFR promotes hepatocellular carcinoma progression through regulating miR-3619-5p/CTNNB1 axis and activating Wnt/ $\beta$-catenin pathway. Arch Biochem Biophys. 2019;661:196-202. doi:10.1016/j.abb.2018.11.020

229. Liu X, Qin J, Gao T, et al. YTHDF1 facilitates the progression of hepatocellular carcinoma by promoting FZD5 mRNA translation in an m6A-dependent manner. Mol Ther Nucleic Acids. 2020;22:750-765. doi:10.1016/j.omtn.2020.09.036 
230. Zhu Q, Lu G, Luo Z, et al. CircRNA circ 0067934 promotes tumor growth and metastasis in hepatocellular carcinoma through regulation of miR-1324/FZD5/Wnt/ $\beta$-catenin axis. Biochem Biophys Res Commun. 2018;497(2):626-632. doi:10.1016/j. bbrc.2018.02.119

231. Chen $\mathrm{CH}$, Su YJ, Ding H, Duan J, Wang J. Circular RNA ZNF292 affects proliferation and apoptosis of hepatocellular carcinoma cells by regulating Wnt/ $\beta$-catenin pathway. Eur Rev Med Pharmacol Sci. 2020;24(23):12124-12130. doi:10.26355/ eurrev_202012_24001

232. Yang B, Zhao J, Huo T, Zhang M, Wu X. Effects of CircRNAITCH on proliferation and apoptosis of hepatocellular carcinoma cells through inhibiting $\mathrm{Wnt} / \beta$-catenin signaling pathway. $J$ BUON. 2020;25(3):1368-1374.

233. Zhu P, Liang H, Huang X, et al. Circular RNA Hsa_circ_0004018 inhibits Wnt/ $\beta$-catenin signaling pathway by targeting microRNA-626/DKK3 in hepatocellular carcinoma. Onco Targets Ther. 2020;13:9351-9364. doi:10.2147/ott.S254997

234. Mirzaei S, Mohammadi AT, Gholami MH, et al. Nrf2 signaling pathway in cisplatin chemotherapy: Potential involvement in organ protection and chemoresistance. Pharmacol Res. 2021;167:105575. doi:10.1016/j.phrs.2021.105575

235. Mirzaei S, Gholami MH, Hashemi F, et al. Employing siRNA tool and its delivery platforms in suppressing cisplatin resistance: approaching to a new era of cancer chemotherapy. Life Sci. 2021;277:119430. doi:10.1016/j.lfs.2021.119430

236. Mirzaei S, Hushmandi K, Zabolian A, et al. Elucidating role of reactive oxygen species (ROS) in cisplatin chemotherapy: a focus on molecular pathways and possible therapeutic strategies. Molecules. 2021;26(8):2382. doi:10.3390/molecules26082382

237. Jin X, Gong L, Peng Y, Li L, Liu G. Enhancer-bound Nrf2 licenses HIF-1 $\alpha$ transcription under hypoxia to promote cisplatin resistance in hepatocellular carcinoma cells. Aging (Albany NY). 2020;13(1):364-375. doi:10.18632/aging.202137

238. Yang Y, Yang $Z$, Zhang R, et al. MiR-27a-3p enhances the cisplatin sensitivity in hepatocellular carcinoma cells through inhibiting PI3K/Akt pathway. Biosci Rep. 2021:BSR20192007. doi:10.1042/bsr20192007

239. Patel SM, Nagulapalli Venkata KC, Bhattacharyya P, Sethi G, Bishayee A. Potential of neem (Azadirachta indica L.) for prevention and treatment of oncologic diseases. Semin Cancer Biol. 2016;40-41:100-115. doi:10.1016/j.semcancer.2016.03.002

240. Li F, Shanmugam MK, Chen L, et al. Garcinol, a polyisoprenylated benzophenone modulates multiple proinflammatory signaling cascades leading to the suppression of growth and survival of head and neck carcinoma. Cancer Prev Res (Phila). 2013;6(8):843-854. doi:10.1158/1940-6207.Capr-13-0070

241. Shanmugam MK, Ong TH, Kumar AP, et al. Ursolic acid inhibits the initiation, progression of prostate cancer and prolongs the survival of TRAMP mice by modulating pro-inflammatory pathways. PLoS One. 2012;7(3):e32476. doi:10.1371/journal. pone. 0032476

242. Manu KA, Shanmugam MK, Ramachandran L, et al. Isorhamnetin augments the anti-tumor effect of capecitabine through the negative regulation of NF- $\mathrm{kB}$ signaling cascade in gastric cancer. Cancer Lett. 2015;363(1):28-36. doi:10.1016/j. canlet.2015.03.033

243. Zeng J, Liu X, Li X, Zheng Y, Liu B, Xiao Y. Daucosterol inhibits the proliferation, migration, and invasion of hepatocellular carcinoma cells via Wnt/ $\beta$-catenin signaling. Molecules. 2017;22 (6):862. doi:10.3390/molecules22060862

244. Wu HC, Lay IS, Shibu MA, et al. Zanthoxylum avicennae extract enhances GSK- $3 \beta$ to attenuate $\beta$-catenin via phosphatase $2 \mathrm{~A}$ to block metastatic effects of HA22T cells and hepatocellular carcinoma xenografted nude mice. Environ Toxicol. 2017;32 (9):2133-2143. doi:10.1002/tox.22426
245. Gong T, Ning X, Deng Z, et al. Propofol-induced miR-219-5p inhibits growth and invasion of hepatocellular carcinoma through suppression of GPC3-mediated Wnt/ $\beta$-catenin signalling activation. J Cell Biochem. 2019;120(10):16934-16945. doi:10.1002/ jcb. 28952

246. Lv MY, Shi CJ, Pan FF, et al. Urolithin B suppresses tumor growth in hepatocellular carcinoma through inducing the inactivation of Wnt/B-catenin signaling. J Cell Biochem. 2019;120 (10):17273-17282. doi:10.1002/jcb.28989

247. He J, Zhao H, Liu X, et al. Sevoflurane suppresses cell viability and invasion and promotes cell apoptosis in colon cancer by modulating exosome-mediated circ-HMGCS1 via the miR-34a5p/SGPP1 axis. Oncol Rep. 2020;44(6):2429-2442. doi:10.3892/ or.2020.7783

248. Song G, Tian L, Cheng Y, et al. Antitumor activity of sevoflurane in HCC cell line is mediated by miR-29a-induced suppression of Dnmt3a. J Cell Biochem. 2019;120(10):18152-18161. doi: $10.1002 /$ jcb.29121

249. Cao Y, Lv W, Ding W, Li J. Sevoflurane inhibits the proliferation and invasion of hepatocellular carcinoma cells through regulating the PTEN/Akt/GSK-3 $\beta / \beta$-catenin signaling pathway by downregulating miR-25-3p. Int $J$ Mol Med. 2020;46(1):97-106. doi:10.3892/ijmm.2020.4577

250. Xie L, Li M, Liu D, et al. Secalonic Acid-F, a novel mycotoxin, represses the progression of hepatocellular carcinoma via MARCH1 regulation of the PI3K/AKT/ $\beta$-catenin signaling pathway. Molecules. 2019;24(3):393. doi:10.3390/molecules24030393

251. Xu Y, Pan S, Jiang W, Xue F, Zhu X. Effects of propofol on the development of cancer in humans. Cell Prolif. 2020;53(8): e12867. doi:10.1111/cpr.12867

252. Ashrafizadeh M, Ahmadi Z, Farkhondeh T, Samarghandian S. Anti-tumor activity of propofol: a focus on MicroRNAs. Curr Cancer Drug Targets. 2020;20(2):104-114. doi:10.2174/ 1568009619666191023100046

253. Ou W, Lv J, Zou X, et al. Propofol inhibits hepatocellular carcinoma growth and invasion through the HMGA2-mediated Wnt/ $\beta$ catenin pathway. Exp Ther Med. 2017;13(5):2501-2506. doi:10.3892/etm.2017.4253

254. Mohammadinejad R, Ahmadi Z, Tavakol S, Ashrafizadeh M. Berberine as a potential autophagy modulator. $J$ Cell Physiol. 2019;234(9):14914-14926. doi:10.1002/jcp.28325

255. Samadi P, Sarvarian P, Gholipour E, et al. Berberine: a novel therapeutic strategy for cancer. IUBMB Life. 2020;72 (10):2065-2079. doi:10.1002/iub.2350

256. Chen J, Wu FX, Luo HL, et al. Berberine upregulates miR-22-3p to suppress hepatocellular carcinoma cell proliferation by targeting Sp1. Am J Transl Res. 2016;8(11):4932-4941.

257. Luo Y, Tian G, Zhuang Z, et al. Berberine prevents non-alcoholic steatohepatitis-derived hepatocellular carcinoma by inhibiting inflammation and angiogenesis in mice. Am $J$ Transl Res. 2019;11(5):2668-2682.

258. Vishnoi K, Ke R, Saini KS, et al. Berberine represses $\beta$-catenin translation involving 4E-BPs in hepatocellular carcinoma cells. $\mathrm{Mol}$ Pharmacol. 2021;99(1):1-16. doi:10.1124/molpharm.120.000029

259. Zou WJ, Huang Z, Jiang TP, et al. Pirfenidone inhibits proliferation and promotes apoptosis of hepatocellular carcinoma cells by inhibiting the Wnt/ $\beta$-catenin signaling pathway. Med Sci Monit. 2017;23:6107-6113. doi:10.12659/msm.907891

260. Jian Q, Yang Z, Shu J, Liu X, Zhang J, Li Z. Lectin BS-I inhibits cell migration and invasion via AKT/GSK-3 $\beta / \beta$-catenin pathway in hepatocellular carcinoma. $J$ Cell Mol Med. 2018;22 (1):315-329. doi:10.1111/jcmm.13320

261. Gabata R, Harada K, Mizutani Y, et al. Anti-tumor activity of the small molecule inhibitor PRI-724 Against $\beta$-catenin-activated hepatocellular carcinoma. Anticancer Res. 2020;40 (9):5211-5219. doi:10.21873/anticanres.14524 
262. Mirzaei S, Mahabady MK, Zabolian A, et al. Small interfering RNA (siRNA) to target genes and molecular pathways in glioblastoma therapy: Current status with an emphasis on delivery systems. Life Sci. 2021;275:119368. doi:10.1016/j.lfs.2021.119368

263. Ashrafizadeh M, Delfi M, Hashemi F, et al. Biomedical application of chitosan-based nanoscale delivery systems: potential usefulness in siRNA delivery for cancer therapy. Carbohydr Polym. 2021;260:117809. doi:10.1016/j.carbpol.2021.117809

264. Zeng G, Apte U, Cieply B, Singh S, Monga SP. siRNA-mediated beta-catenin knockdown in human hepatoma cells results in decreased growth and survival. Neoplasia. 2007;9(11):951-959. doi:10.1593/neo.07469

265. Wang XH, Sun X, Meng XW, et al. beta-catenin siRNA regulation of apoptosis- and angiogenesis-related gene expression in hepatocellular carcinoma cells: potential uses for gene therapy. Oncol Rep. 2010;24(4):1093-1099.

266. Ashrafizadeh M, Zarrabi A, Hushmandi K, et al. Progress in Natural Compounds/siRNA Co-delivery Employing Nanovehicles for Cancer Therapy. ACS Comb Sci. 2020;22 (12):669-700. doi:10.1021/acscombsci.0c00099

267. Ashrafizadeh M, Hushmandi K, Rahmani Moghadam E, et al. Progress in delivery of siRNA-based therapeutics employing nano-vehicles for treatment of prostate cancer. Bioengineering (Basel). 2020;7(3):91. doi:10.3390/bioengineering7030091

268. Ashrafizadeh M, Mirzaei S, Gholami MH, et al. Hyaluronic acid-based nanoplatforms for Doxorubicin: A review of stimuli-responsive carriers, co-delivery and resistance suppression. Carbohydr Polym. 2021;272:118491. doi:10.1016/j. carbpol.2021.118491

269. Xu Y, Zhang C, Liang H, et al. Dishevelled 1, a pivotal positive regulator of the Wnt signalling pathway, mediates 5-fluorouracil resistance in HepG2 cells. Artif Cells Nanomed Biotechnol. 2018;46(sup2):192-200. doi:10.1080/21691401.2018.1453827

270. Cai J, Chen J, Wu T, et al. Genome-scale CRISPR activation screening identifies a role of LRP8 in Sorafenib resistance in Hepatocellular carcinoma. Biochem Biophys Res Commun. 2020;526(4):1170-1176. doi:10.1016/j.bbrc.2020.04.040

271. Xu N, Shen C, Luo Y, et al. Upregulated miR-130a increases drug resistance by regulating RUNX3 and Wnt signaling in cisplatin-treated HCC cell. Biochem Biophys Res Commun. 2012;425(2):468-472. doi:10.1016/j.bbrc.2012.07.127

272. Liu Y, Zhuang H, Cao F, et al. Shc3 promotes hepatocellular carcinoma stemness and drug resistance by interacting with $\beta$ catenin to inhibit its ubiquitin degradation pathway. Cell Death Dis. 2021;12(3):278. doi:10.1038/s41419-021-03560-8

273. Cao MQ, You AB, Zhu XD, et al. miR-182-5p promotes hepatocellular carcinoma progression by repressing FOXO3a. J Hematol Oncol. 2018;11(1):12. doi:10.1186/s13045-018-0555-y

274. Chen Y, Zhang F, Zhao Y, et al. Obesity-associated miR-27a upregulation promotes hepatocellular carcinoma metastasis through suppressing SFRP1. Onco Targets Ther 2018;11:3281-3292. doi:10.2147/ott.S162978

275. Kong X, Liu F, Gao J. MiR-155 promotes epithelial-mesenchymal transition in hepatocellular carcinoma cells through the activation of PI3K/SGK3/ $\beta$-catenin signaling pathways. Oncotarget. 2016;7 (40):66051-66060. doi:10.18632/oncotarget.11800

276. Zhang Z, Yin J, Yang J, et al. miR-885-5p suppresses hepatocellular carcinoma metastasis and inhibits $\mathrm{Wnt} / \beta$-catenin signaling pathway. Oncotarget. 2016;7(46):75038-75051. doi:10.18632/ oncotarget. 12602

277. Yang C, Xu Y, Cheng F, et al. miR-1301 inhibits hepatocellular carcinoma cell migration, invasion, and angiogenesis by decreasing Wnt/ $\beta$-catenin signaling through targeting BCL9. Cell Death Dis. 2017;8(8):e2999. doi:10.1038/cddis.2017.356
278. Cao F, Yin LX. miR-122 enhances sensitivity of hepatocellular carcinoma to oxaliplatin via inhibiting MDR1 by targeting Wnt/ $\beta$ catenin pathway. Exp Mol Pathol. 2019;106:34-43. doi:10.1016/j. yexmp.2018.10.009

279. Jin Y, Wang J, Han J, Luo D, Sun Z. MiR-122 inhibits epithelialmesenchymal transition in hepatocellular carcinoma by targeting Snail1 and Snail2 and suppressing WNT/B-cadherin signaling pathway. Exp Cell Res. 2017;360(2):210-217. doi:10.1016/j. yexcr.2017.09.010

280. Sun L, Wang L, Chen T, et al. LncRNA RUNX1-IT1 which is downregulated by hypoxia-driven histone deacetylase 3 represses proliferation and cancer stem-like properties in hepatocellular carcinoma cells. Cell Death Dis. 2020;11(2):95. doi:10.1038/ s41419-020-2274-x

281. Wu Y, Zhou Y, Huan L, et al. LncRNA MIR22HG inhibits growth, migration and invasion through regulating the miR-10a$5 \mathrm{p} / \mathrm{NCOR} 2$ axis in hepatocellular carcinoma cells. Cancer Sci. 2019;110(3):973-984. doi:10.1111/cas.13950

282. Yan X, Zhang D, Wu W, et al. Mesenchymal Stem Cells Promote Hepatocarcinogenesis via lncRNA-MUF Interaction with ANXA2 and miR-34a. Cancer Res. 2017;77(23):6704-6716. doi:10.1158/0008-5472.Can-17-1915

283. Yu G, Wang W, Deng J, Dong S. LncRNA AWPPH promotes the proliferation, migration and invasion of ovarian carcinoma cells via activation of the Wnt/ $\beta$-catenin signaling pathway. Mol Med Rep. 2019;19(5):3615-3621. doi:10.3892/mmr.2019.10029

284. Zhu L, Yang N, Du G, et al. LncRNA CRNDE promotes the epithelial-mesenchymal transition of hepatocellular carcinoma cells via enhancing the $\mathrm{Wnt} / \beta$-catenin signaling pathway. $J$ Cell Biochem. 2018;120(2):1156-1164. doi:10.1002/jcb.26762

285. Lin Z, Liu J. IncRNA DQ786243 promotes hepatocellular carcinoma cell invasion and proliferation by regulating the miR-15p-5p/Wnt3A axis. Mol Med Rep. 2021;23(5):318. doi:10.3892/mmr.2021.11957

286. Lee J, Zhou W, Na M, Oh S. Cytotoxic activity of aplykurodin a isolated from aplysia kurodai against AXIN1-mutated hepatocellular carcinoma cells by promoting oncogenic $\beta$-catenin degradation. Mar Drugs. 2020;18(4):210. doi:10.3390/md18040210

287. Al Refaey HR, Newairy AA, Wahby MM, et al. Manuka honey enhanced sensitivity of HepG2, hepatocellular carcinoma cells, for Doxorubicin and induced apoptosis through inhibition of Wnt/ $\beta$-catenin and ERK1/2. Biol Res. 2021;54(1):16. doi:10.1186/ s40659-021-00339-1

288. Huang D, Yang B, Yao Y, et al. Autophagic inhibition of Caveolin-1 by compound phyllanthus urinaria L. Activates ubiquitination and proteasome degradation of $\beta$-catenin to suppress metastasis of hepatitis B-associated hepatocellular carcinoma. Front Pharmacol. 2021;12:659325. doi:10.3389/fphar.2021.659325

289. Fan X, Song J, Zhao Z, et al. Piplartine suppresses proliferation and invasion of hepatocellular carcinoma by LINC01391modulated Wnt/ $\beta$-catenin pathway inactivation through ICAT. Cancer Lett. 2019;460:119-127. doi:10.1016/j.canlet.2019.06.008

290. Hung MH, Chen YL, Chen LJ, et al. Canagliflozin inhibits growth of hepatocellular carcinoma via blocking glucose-influxinduced $\beta$-catenin activation. Cell Death Dis. 2019;10(6):420. doi:10.1038/s41419-019-1646-6

291. Shi L, Yang F, Luo F, et al. Evodiamine exerts anti-tumor effects against hepatocellular carcinoma through inhibiting $\beta$-cateninmediated angiogenesis. Tumour Biol. 2016;37(9):12791-12803. doi:10.1007/s13277-016-5251-3

292. Cheng Z, Yuan X, Qu Y, et al. Bruceine D inhibits hepatocellular carcinoma growth by targeting $\beta$-catenin/jagged1 pathways. Cancer Lett. 2017;403:195-205. doi:10.1016/j.canlet.2017.06.014 
293. Chen T, Lin J, Tang D, et al. Paris saponin H suppresses human hepatocellular carcinoma (HCC) by inactivation of $\mathrm{Wnt} / \beta$-catenin pathway in vitro and in vivo. Int J Clin Exp Pathol. 2019;12 (8):2875-2886.

294. Jeon T, Ko MJ, Seo YR, et al. Silencing CDCA8 suppresses hepatocellular carcinoma growth and stemness via restoration of ATF3 tumor suppressor and inactivation of AKT $/ \beta$-catenin signaling. Cancers (Basel). 2021;13(5):1055. doi:10.3390/cancers13051055

295. Ho NPY, Leung CON, Wong TL, et al. The interplay of UBE2T and Mule in regulating $\mathrm{Wnt} / \beta$-catenin activation to promote hepatocellular carcinoma progression. Cell Death Dis. 2021;12 (2):148. doi:10.1038/s41419-021-03403-6

296. Wu Q, Xu C, Zeng X, Zhang Z, Yang B, Rao Z. Tumor suppressor role of sFRP-4 in hepatocellular carcinoma via the Wnt/ $\beta$-catenin signaling pathway. Mol Med Rep. 2021;23(5):336. doi:10.3892/mmr.2021.11975

297. Feng S, Liu J, Hailiang L, et al. Amplification of RAD54B promotes progression of hepatocellular carcinoma via activating the Wnt/ $\beta$-catenin signaling. Transl Oncol. 2021;14(8):101124. doi:10.1016/j.tranon.2021.101124

298. Hu JW, Yin Y, Gao Y, et al. TM2D1 contributes the epithelialmesenchymal transition of hepatocellular carcinoma via modulating AKT/ $\beta$-catenin axis. Am $J$ Cancer Res. 2021;11 (4):1557-1571.
299. Yi Y, Yu MC, Fu PY, et al. MNS1 promotes hepatocarcinogenesis and metastasis via activating PI3K/AKT by translocating $\beta$ catenin and predicts poor prognosis. Liver Int. 2021;41 (6):1409-1420. doi:10.1111/liv.14803

300. Chen D, Yan Y, Wang X, et al. Chronic alcohol exposure promotes HCC stemness and metastasis through $\beta$-catenin/miR-223p/TET2 axis. Aging (Albany NY). 2021;13(10):14433-14455. doi:10.18632/aging.203059

301. Wei S, Dai M, Zhang C, et al. KIF2C: a novel link between Wnt/ $\beta$-catenin and mTORC1 signaling in the pathogenesis of hepatocellular carcinoma. Protein Cell. 2020;12(10):788-809. doi:10.1007/s13238-020-00766-y

302. Cadoux M, Caruso S, Pham S, et al. Expression of NKG2D ligands is downregulated by $\beta$-catenin signalling and associates with HCC aggressiveness. J Hepatol. 2021;74(6):1386-1397. doi:10.1016/j.jhep.2021.01.017

303. Hou J, Zhao N, Zhu P, Chang J, Du Y, Shen W. Irradiated mesenchymal stem cells support stemness maintenance of hepatocellular carcinoma stem cells through Wnt/ $\beta$-catenin signaling pathway. Cell Biosci. 2020;10:93. doi:10.1186/s13578-02000449-5
Journal of Hepatocellular Carcinoma

\section{Publish your work in this journal}

The Journal of Hepatocellular Carcinoma is an international, peerreviewed, open access journal that offers a platform for the dissemination and study of clinical, translational and basic research findings in this rapidly developing field. Development in areas including, but not limited to, epidemiology, vaccination, hepatitis therapy, pathology

\section{Dovepress}

and molecular tumor classification and prognostication are al considered for publication. The manuscript management system is completely online and includes a very quick and fair peer-review system, which is all easy to use. Visit http://www.dovepress.com/ testimonials.php to read real quotes from published authors. 